\title{
A functional time series analysis of forward curves derived from commodity futures
}

Article

Accepted Version

Creative Commons: Attribution-Noncommercial-No Derivative Works 4.0

Horváth, L., Liu, Z., Rice, G. and Wang, S. (2020) A functional time series analysis of forward curves derived from commodity futures. International Journal of Forecasting, 36 (2). pp. 646665. ISSN 0169-2070 doi:

https://doi.org/10.1016/j.ijforecast.2019.08.003 Available at https://centaur.reading.ac.uk/85666/

It is advisable to refer to the publisher's version if you intend to cite from the work. See Guidance on citing.

To link to this article DOI: http://dx.doi.org/10.1016/j.ijforecast.2019.08.003

Publisher: Elsevier

All outputs in CentAUR are protected by Intellectual Property Rights law, including copyright law. Copyright and IPR is retained by the creators or other copyright holders. Terms and conditions for use of this material are defined in the End User Agreement.

www.reading.ac.uk/centaur 
Central Archive at the University of Reading

Reading's research outputs online 


\title{
A Functional Time Series Analysis of Forward Curves \\ Derived from Commodity Futures
}

\begin{abstract}
We study forward curves formed from commodity futures prices listed on the Standard and Poor's-Goldman Sachs Commodities Index (S\&P GSCI) using recently developed tools in functional time series analysis. Functional tests for stationarity and serial correlation suggest that log-differenced forward curves may be generally considered as stationary and conditionally heteroscedastic sequences of functions. Several functional methods for forecasting forward curves that more accurately reflect the time to expiry of contracts are developed, and we found that these typically outperformed their multivariate counterparts, with the best among them using the method of predictive factors introduced by Kargin \& Onatski (2008).
\end{abstract}

Keywords: Forward curves, S\&P GSCI, Commodity Futures, Functional Data Analysis, Functional Autoregressive Models, Functional Principal Component Analysis JEL: C12, C32, C58, G15, G17, Q02 


\section{Introduction}

Commodity futures are one of the most widely traded types of financial assets. One reason for this is that they provide risk diversification for portfolio management, since the returns on commodity futures are negatively correlated with the return on stocks and bonds Gorton \& Rouwenhorst, 2006, Bhardwaj et al., 2015). The forward curve, also referred to as the futures term structure, is formed by the futures/forward prices for a particular commodity over all available maturities at a certain point in time. Empirically, commodity futures behave quite differently when compared to other conventional financial assets, such as stocks and bonds. Their stylized properties include normal backwardation (Litzenberger \& Rabinowitz, 1995), mean reversion (Bessembinder et al., 1995; Kocagil et al., 2001), strong heteroscedasticity (Duffie et al., 1999), positive correlation between price volatility and the degree of backwardation $(\mathrm{Ng}$ \& Pirrong, 1994; Litzenberger \& Rabinowitz, 1995), the "Samuelson effect" (Samuelson, 1965), and pronounced seasonality (Sørensen, 2002). Each of these terms generally describe the shape and evolution of forward curves over time. See also (Routledge et al. 2000) for a summary of these findings.

Forward curves derived from commodity futures are important for both academic researchers and financial practitioners. From the academic perspective, the information contained in the forward curves (such as shape, slope, roll-yield) are essential input factors in pricing models of commodities (Schwartz \& Smith, 2000, Pilipovic, 2007; Chong et al., 2017) and predictive factors for futures returns (Gorton et al. 2013). They can also be related to volatility of spot and futures prices (Haugom \& Ullrich, 2012, Kogan et al., 2009). For practitioners forward curves are one of the key factors in investment decisions on commodities. A number of commodity trading strategies are built, fully or partially, on the forward curves (Mou, 2010, Fuertes et al., 2015, Gomes, 2015). Mou (2010) designed trading strategies to take advantage of the resulting impact on forward curves from the rolling activity conducted by commodity index funds on the Standard and Poor's-Goldman Sachs Commodity Index (S\&P GSCI).

Without a doubt these methods could be improved with useful forecasts of full forward curves, although, to the best of our knowledge, little attention has been paid to this issue in the literature. The problem of forecasting forward curves is similar to that of forecasting the term structure of interest rates, which enjoys a comparably abundant and expanding literature (see Duffee et al. 2012, Diebold \& Rudebusch, 2013, for a review). Among those methods, one of the most popular was developed by Diebold \& Li (2006), who proposed a dynamic Nelson-Siegel model 
(DNS) to forecast the yield curve as a three-dimensional parameter vector evolving dynamically. The three time-varying parameters in their model correspond to level, slope, and curvature. Many extensions of the DNS model have been proposed. Xiang \& Zhu (2013) developed a DNS term structure model subject to regime shifts, and Byrne et al. (2017) extended the DNS model to allow the model dimension and the parameters to change over time. Their version of DNS considers a large set of macro-financial factors to characterize the nonlinear dynamics of yield factors.

The available literature on forecasting futures prices focuses primarily on the active contract $\mathrm{D}^{1}$ or front-month contract price (e.g. Moskowitz et al., 2012). Chantziara \& Skiadopoulos (2008) employed principal component analysis (PCA) to investigate whether the daily evolution of the forward curves of petroleum futures (NYMEX crude oil, heating oil, gaosline, and IPE crude oil futures) can be forecasted, and found that the retained principal components have small forecasting power measured both within a training sample and out-of-sample. Baruník \& Malinska (2016) proposed to forecast the forward curves of oil futures by coupling dynamic neural networks with the Nelson-Siegel model. Their forecasting strategy outperformed other benchmark models (vector autoregressive and random walk models) for crude oil futures prices. Grønborg \& Lunde (2016) applied DNS model for the forward curves of oil futures contracts and obtained forecasts of prices of these contracts. Evaluated by the criteria of model confidence sets (Hansen et al. 2011), their models produce better forecasting results than conventional benchmarks (autoregressive and VAR). Power et al. (2017) used wavelet thresholding to denoise futures price data before estimating a state-space model. For their sample of CBOT corn futures, de-noising the data by wavelet thresholding improved forecasting results in most cases. These forecasting methods build upon a large literature devoted to factor models for commodity futures (see Gibson \& Schwartz, 1990; Litterman \& Scheinkman, 1991, Schwartz \& Smith, 2000, Tolmasky \& Hindanov, 2002).

An important distinction in each of the above models is that they intrinsically treat the futures prices and forward curves as multivariate objects. This is natural to do since, for example, the futures prices of a commodity with contracts expiring each month in a twelve month period can be considered as a twelve dimensional vector. Doing so does, however, come with some information loss, since the components of such a vector will correspond to only approximate

\footnotetext{
${ }^{1}$ The active contract for a particular commodity is normally considered to be the contract with highest trading volume among all available maturities.
} 
information on the time to expiry of the available contracts.

A less explored framework which offers new insight into this data is to consider them as sparse observations from an underlying continuous futures price curve. To illustrate, for a given commodity on day $i$ with $J$ available contracts, futures price information can be represented by $P_{i}\left(t_{i, j}\right)$, where the $t_{i, j}, j \in\{1,2, \ldots, J\}$, represent the time to expiration of the available contracts. Importantly, these times change each day and roll from one month to the next. This can easily be accounted for by interpolating the available contract prices in order to produce an estimate for the full forward curve, $P_{i}^{(C)}(t)$, and the series of these forward curves can be analyzed by functional time series analysis. The scope of methodology for analyzing such functional time series has increased tremendously since the seminal work of Bosq (2000) on the topic, see Hörmann \& Kokoszka (2012) for a more recent review.

In this paper, we consider the analysis and predication of forward curves as functional data objects. In defining the forward curves as functional data, an important distinction is how one defines the time to expiry of a given contract. Defining this time in months gives rise to essentially equivalent methods as the available multivariate techniques referenced above, while using a higher resolution, like days or weeks, leads to quite different methods. It is shown below using recently developed tools in functional time series analysis that the log-differenced forward curves over several different temporal resolutions are reasonably stationary. We further show that for many commodities these curves can be thought of as weak functional white noises exhibiting conditional heteroscedasticity, suggesting that the forward curves evolve approximately as martingales. In several cases though the forward curves appear predictable in that they exhibit substantial autocorrelation. Given this, several models for forecasting forward curves are proposed and studied in a comprehensive data analysis. This analysis suggests that 1) measuring time to expiry of contracts in terms of days provides a significant improvement in terms of forecasting accuracy, and 2) the functional forecasting methods tend to outperform multivariate techniques, and in several cases are able to beat naïve forecasts in out-of-sample evaluations.

The rest of the paper is organized as follows. In Section 2, we discuss how we obtained and used the raw futures contract data in order to construct functional data objects at various temporal resolutions. Section 3 presents a functional time series analysis of the log-differenced forward curves, in particular presenting the results of stationarity and white noise tests to measure their suitability to be modelled with using stationary functional time series models. Methods for forecasting forward curves are put forward and compared in an extensive data analysis of commodity futures listed on the S\&P GSCI in Section 4 Some concluding remarks and a 
summary of this work is given in Section 5, and some technical details about the stationarity and white noise tests as well as further results from the data analysis are presented in Appendix A.

Briefly we define some of the notation that we use below. We use $\mathbb{E}(\cdot)$ to denote mathematical expectation. We let $L^{2}[0,1]^{d}$ denote the space of real valued square integrable functions defined on unit hypercube $[0,1]^{d}$ of dimension $d$ with norm $\|\cdot\|$ induced by the inner product $\langle x, y\rangle=$ $\int_{0}^{1} \cdots \int_{0}^{1} x\left(t_{1}, \ldots, t_{d}\right) y\left(t_{1}, \ldots, t_{d}\right) d t_{1} \ldots d t_{d}$ for $x, y \in L^{2}[0,1]^{d}$, the dimension of the domain being clear based on the input function. Henceforth we write $\int$ instead of $\int_{0}^{1}$. We use $\stackrel{D}{\longrightarrow}$ to denote convergence in distribution.

\section{Forward curves as functional data objects}

In this section, we detail how we obtained the data that we consider below, and how it was transformed into functional data objects.

\subsection{Basic Information on Data}

The widely tracked S\&P GSCI is recognized as a leading measure of general price movements of commodity futures, and it is designed to be investable by including the most liquid commodity futures. There are 24 commodity futures in the current basket of S\&P GSCL ${ }^{2}$ and we considered each of them in our analysis. Table 1 gives information on these commodities, including the available contract months for each commodity. The expiry of included futures contracts is limited to a maximum of 1 year, as trading activity and liquidity decline sharply with increasing time to maturity (Dürr \& Voegeli, 2009). We did not include spot prices in our analysis because the observable prices of some of the commodities considered do not exist, and further empirical studies have shown there are discrepancies between the real spot price and futures prices Irwin et al. 2009).

The raw data that we consider are generic futures time series for these commodities, which we downloaded from a Bloomberg termina $]^{3}$, and consists of daily records (in most cases) from January 3rd, 2000 to August 31st, 20174 Continuous generic futures time series are constructed

\footnotetext{
2 http://us.spindices.com/index-family/commodities/sp-gsci

${ }^{3}$ The raw data was downloaded using the Bloomberg-R API of the R Package "Rblpapi" Armstrong et al. 2017).

${ }^{4}$ The detailed data information is reported in Table 11 in Appendix $\mathrm{C}$
} 
Table 1: Commodity Futures Information

\begin{tabular}{|c|c|c|c|c|c|c|c|c|c|c|c|c|c|c|}
\hline \multirow[b]{2}{*}{ Symbol } & \multirow[b]{2}{*}{ Name } & \multirow[b]{2}{*}{ Exchange } & \multicolumn{12}{|c|}{ Contract Month } \\
\hline & & & Jan & $\mathrm{Feb}$ & Mar & Apr & May & Jun & Jul & Aug & Sep & Oct & Nov & Dec \\
\hline FC & Feeder Cattle & CME & $\checkmark$ & & $\checkmark$ & $\checkmark$ & $\checkmark$ & & & $\checkmark$ & $\checkmark$ & $\checkmark$ & $\checkmark$ & \\
\hline LC & Live Cattle & CME & & $\checkmark$ & & $\checkmark$ & & $\checkmark$ & & $\checkmark$ & & $\checkmark$ & & $\checkmark$ \\
\hline LH & Lean Hogs & $\mathrm{CME}$ & & $\checkmark$ & & $\checkmark$ & & $\checkmark$ & $\checkmark$ & $\checkmark$ & & $\checkmark$ & & $\checkmark$ \\
\hline $\mathbf{C}$ & Corn & $\mathrm{CBOT}$ & & & $\checkmark$ & & $\checkmark$ & & $\checkmark$ & & $\checkmark$ & & & $\checkmark$ \\
\hline $\mathrm{S}$ & Soybean & $\mathrm{CBOT}$ & $\checkmark$ & & $\checkmark$ & & $\checkmark$ & & $\checkmark$ & $\checkmark$ & $\checkmark$ & & $\checkmark$ & \\
\hline $\mathbf{W}$ & Wheat & $\mathrm{CBOT}$ & & & $\checkmark$ & & $\checkmark$ & & $\checkmark$ & & $\checkmark$ & & & $\checkmark$ \\
\hline $\mathrm{CC}$ & Cocoa & $\mathrm{ICE}$ & & & $\checkmark$ & & $\checkmark$ & & $\checkmark$ & & $\checkmark$ & & & $\checkmark$ \\
\hline KC & Coffee & $\mathrm{ICE}$ & & & $\checkmark$ & & $\checkmark$ & & $\checkmark$ & & $\checkmark$ & & & $\checkmark$ \\
\hline KW & Kansas Wheat & KBOT & & & $\checkmark$ & & $\checkmark$ & & $\checkmark$ & & $\checkmark$ & & & $\checkmark$ \\
\hline CT & Cotton & ICE & & & $\checkmark$ & & $\checkmark$ & & $\checkmark$ & & & $\checkmark$ & & $\checkmark$ \\
\hline SB & Sugar & ICE & & & $\checkmark$ & & $\checkmark$ & & $\checkmark$ & & & $\checkmark$ & & \\
\hline LA & Aluminum & LME & $\checkmark$ & $\checkmark$ & $\checkmark$ & $\checkmark$ & $\checkmark$ & $\checkmark$ & $\checkmark$ & $\checkmark$ & $\checkmark$ & $\checkmark$ & $\checkmark$ & $\checkmark$ \\
\hline LL & Lead & LME & $\checkmark$ & $\checkmark$ & $\checkmark$ & $\checkmark$ & $\checkmark$ & $\checkmark$ & $\checkmark$ & $\checkmark$ & $\checkmark$ & $\checkmark$ & $\checkmark$ & $\checkmark$ \\
\hline $\mathbf{L P}$ & Copper & LME & $\checkmark$ & $\checkmark$ & $\checkmark$ & $\checkmark$ & $\checkmark$ & $\checkmark$ & $\checkmark$ & $\checkmark$ & $\checkmark$ & $\checkmark$ & $\checkmark$ & $\checkmark$ \\
\hline GC & Gold & COMEX & & $\checkmark$ & & $\checkmark$ & & $\checkmark$ & & $\checkmark$ & & $\checkmark$ & & $\checkmark$ \\
\hline LN & Nickel & LME & $\checkmark$ & $\checkmark$ & $\checkmark$ & $\checkmark$ & $\checkmark$ & $\checkmark$ & $\checkmark$ & $\checkmark$ & $\checkmark$ & $\checkmark$ & $\checkmark$ & $\checkmark$ \\
\hline SI & Silver & COMEX & $\checkmark$ & & $\checkmark$ & & $\checkmark$ & & $\checkmark$ & & $\checkmark$ & & & $\checkmark$ \\
\hline LX & Zinc & LME & $\checkmark$ & $\checkmark$ & $\checkmark$ & $\checkmark$ & $\checkmark$ & $\checkmark$ & $\checkmark$ & $\checkmark$ & $\checkmark$ & $\checkmark$ & $\checkmark$ & $\checkmark$ \\
\hline CL & Light Crude Oil & NYMEX & $\checkmark$ & $\checkmark$ & $\checkmark$ & $\checkmark$ & $\checkmark$ & $\checkmark$ & $\checkmark$ & $\checkmark$ & $\checkmark$ & $\checkmark$ & $\checkmark$ & $\checkmark$ \\
\hline $\mathrm{CO}$ & Brent Crude Oil & $\mathrm{ICE}$ & $\checkmark$ & $\checkmark$ & $\checkmark$ & $\checkmark$ & $\checkmark$ & $\checkmark$ & $\checkmark$ & $\checkmark$ & $\checkmark$ & $\checkmark$ & $\checkmark$ & $\checkmark$ \\
\hline HO & Heating Oil & NYMEX & $\checkmark$ & $\checkmark$ & $\checkmark$ & $\checkmark$ & $\checkmark$ & $\checkmark$ & $\checkmark$ & $\checkmark$ & $\checkmark$ & $\checkmark$ & $\checkmark$ & $\checkmark$ \\
\hline PG & Gasoline & $\mathrm{ICE}$ & $\checkmark$ & $\checkmark$ & $\checkmark$ & $\checkmark$ & $\checkmark$ & $\checkmark$ & $\checkmark$ & $\checkmark$ & $\checkmark$ & $\checkmark$ & $\checkmark$ & $\checkmark$ \\
\hline NG & Natural Gas & NYMEX & $\checkmark$ & $\checkmark$ & $\checkmark$ & $\checkmark$ & $\checkmark$ & $\checkmark$ & $\checkmark$ & $\checkmark$ & $\checkmark$ & $\checkmark$ & $\checkmark$ & $\checkmark$ \\
\hline $\mathrm{XB}$ & RBOB Gasoline & NYMEX & $\checkmark$ & $\checkmark$ & $\checkmark$ & $\checkmark$ & $\checkmark$ & $\checkmark$ & $\checkmark$ & $\checkmark$ & $\checkmark$ & $\checkmark$ & $\checkmark$ & $\checkmark$ \\
\hline
\end{tabular}


from actual futures prices in order of their relative expiration. For example, for a given commodity on day $i$, the price of the next (first) expiring contract can be denoted as $P_{i}\left(t_{i, 1}\right)$, where $t_{i, 1}$ is the amount of time until the next contract expires. Similarly one may obtain prices of contracts expiring in $t_{i, j}$ time units, $P_{i}\left(t_{i, 2}\right), \ldots, P_{i}\left(t_{i, J}\right)$, when $J$ contract months are available. For many commodities with contracts available in each month, $J=12$. The curves constructed from these price data, which we denote $P_{i}^{(C)}(t)$, are commonly referred to as the forward curves, and are often displayed after linear interpolation of the available contracts assuming the time increments $t_{i, j}$ are measured in months until expiry.

The time points at which price information is available are regularly changing (Schwartz, 1997; Grønborg \& Lunde, 2016; Jin, 2017). This is caused by two sources. Firstly, the maturity of all contracts in the full contract chain decreases daily. The second source is due to rolling. At the date the front month contract expires, there is a jump to the expiry date of the next contract. Due to the nature of the irregular sampling time points in forward curves, traditional multivariate analysis techniques that treat the available contract prices as a multivariate vector with a balanced design are somewhat ill posed, since the coordinates correspond to contracts expiring at variable dates in the future. In addition, the time to expiry of futures contracts could be measured at several different temporal resolutions. Classically, this time is measured in months, although it is more accurate to measure the time to expiration in weeks or days. Table 2 describes the contract chain for the Corn futures and their maturity in the three resolutions of months, weeks and days to expiry during July $10^{\text {th }} 2017$ and July $19^{\text {th }} 2017$. The front contract rolled from the contract expiring in July $\left(C N^{r}\right.$ ) to the contract expiring in September $\left(C U^{r}\right)$ on July $17^{\text {th }}$, due to the expiration of $C N \%$. Figure 1 shows the corresponding segments of the forward curves, which are obtained by linear interpolation from $P_{i}\left(t_{i, j}\right) j=1, \ldots ., 5$ with $t_{i, j}$ measured at a daily resolution. Below we consider daily, weekly, and monthly resolutions for the times to expiry $t_{i, j}$.

Given the raw prices $P_{i}\left(t_{i, j}\right), j=1, \ldots ., J$, and a choice of the time resolution for a commodity, one can complete this data to full forward curves $P_{i}^{(C)}(t)$ using a number of methods. It is most typical in functional data analysis to perform this step using interpolation or smoothing techniques. One key difference in the interpretation of using interpolation versus smoothing to produce curves in this setting is the following: interpolation techniques effectively assume that the available contract prices are observed without error, while smoothing methods might be deemed more appropriate when the observed prices are thought to be contaminated by error, in which case a roughness penalty might be employed to derive fitted curves that ideally smooth through the 
Table 2: Actual available contracts for Corn futures from 10 days in 2017, as well as the maturities of each contract in three resolutions.

\begin{tabular}{|c|c|c|c|c|c|}
\hline & \multicolumn{5}{|c|}{ Actual Contracts Ticker } \\
\hline & Generic 1 & Generic 2 & Generic 3 & Generic 4 & Generic 5 \\
\hline 2017-07-10 & C N7 & C U7 & $\mathrm{C} \mathrm{Z7}$ & $\mathrm{C} \mathrm{H} 8$ & $\mathrm{C} \mathrm{K} 8$ \\
\hline 2017-07-11 & C N7 & C U7 & C Z7 & $\mathrm{C} \mathrm{H} 8$ & C K8 \\
\hline 2017-07-12 & $\mathrm{C}$ N7 & C U7 & $\mathrm{C} \mathrm{Z7}$ & $\mathrm{C} \mathrm{H} 8$ & $\mathrm{C} \mathrm{K} 8$ \\
\hline 2017-07-13 & $\mathrm{C}$ N7 & C U7 & C Z7 & $\mathrm{C} \mathrm{H} 8$ & $\mathrm{C} \mathrm{K} 8$ \\
\hline 2017-07-14 & C N7 & C U7 & $\mathrm{C} \mathrm{Z7}$ & $\mathrm{C} \mathrm{H} 8$ & $\mathrm{C} \mathrm{K} 8$ \\
\hline 2017-07-17 & C U7 & C Z7 & $\mathrm{C} \mathrm{H} 8$ & $\mathrm{C} \mathrm{K} 8$ & $\mathrm{C}$ N8 \\
\hline 2017-07-18 & C U7 & $\mathrm{C} \mathrm{Z7}$ & $\mathrm{C} \mathrm{H} 8$ & $\mathrm{C} \mathrm{K} 8$ & $\mathrm{C}$ N8 \\
\hline \multirow[t]{2}{*}{ 2017-07-19 } & C U7 & C Z7 & $\mathrm{C} \mathrm{H8}$ & C K8 & $\mathrm{C}$ N8 \\
\hline & \multicolumn{5}{|c|}{ Resolution: Daily } \\
\hline 2017-07-10 & 4 & 66 & 157 & 247 & 308 \\
\hline 2017-07-11 & 3 & 65 & 156 & 246 & 307 \\
\hline 2017-07-12 & 2 & 64 & 155 & 245 & 306 \\
\hline 2017-07-13 & 1 & 63 & 154 & 244 & 305 \\
\hline 2017-07-14 & 0 & 62 & 153 & 243 & 304 \\
\hline 2017-07-17 & 59 & 150 & 240 & 301 & 361 \\
\hline 2017-07-18 & 58 & 149 & 239 & 300 & 360 \\
\hline \multirow[t]{2}{*}{ 2017-07-19 } & 57 & 148 & 238 & 299 & 359 \\
\hline & \multicolumn{5}{|c|}{ Resolution: Weekly } \\
\hline 2017-07-10 & 0 & 9 & 22 & 35 & 44 \\
\hline 2017-07-11 & 0 & 9 & 22 & 35 & 43 \\
\hline 2017-07-12 & 0 & 9 & 22 & 35 & 43 \\
\hline 2017-07-13 & 0 & 9 & 22 & 34 & 43 \\
\hline 2017-07-14 & 0 & 8 & 21 & 34 & 43 \\
\hline 2017-07-17 & 8 & 21 & 34 & 43 & 51 \\
\hline 2017-07-18 & 8 & 21 & 34 & 42 & 51 \\
\hline \multirow[t]{2}{*}{ 2017-07-19 } & 8 & 21 & 34 & 42 & 51 \\
\hline & \multicolumn{5}{|c|}{ Resolution: Monthly } \\
\hline 2017-07-10 & 0 & 2 & 5 & 8 & 10 \\
\hline 2017-07-11 & 0 & 2 & 5 & 8 & 10 \\
\hline 2017-07-12 & 0 & 2 & 5 & 8 & 10 \\
\hline 2017-07-13 & 0 & 2 & 5 & 8 & 10 \\
\hline 2017-07-14 & 0 & 2 & 5 & 8 & 10 \\
\hline 2017-07-17 & 2 & 5 & 8 & 10 & 12 \\
\hline 2017-07-18 & 2 & 5 & 8 & 10 & 12 \\
\hline 2017-07-19 & 2 & 5 & 8 & 10 & 12 \\
\hline
\end{tabular}

Note: The contract ticker denotes the specific commodity futures contract with the expiry month and year: $1^{\text {st }}$ letter $-\mathrm{C}$ (Corn); $2^{\text {nd }}$ letter $-\mathrm{H}$ (March), K (May), N (July), U (September) \& Z (December); and last number -7 (2017) \& 8(2018). For example, $C N 7$ is the corn contract expired in July 2017. The termination of trading of Corn futures on CBOT is the business day prior to the $15^{\text {th }}$ calendar day of the contract month. The last trade day of $C N 7$ is on $14^{\text {th }}$ July 2017 . We define the time to expiration in three resolutions as follows. Daily resolution: the number of days between the last trade day and the current date. Weekly resolution: the number of weeks between the last trade day and the current date. If it comes to the same week of the last trade day, the time to expiration in weeks is set to be zero. Monthly resolution: the number of months between the last trade day and the current date. If it comes to the same month of the last trade day, the time to expiration in months is set to be zero. 


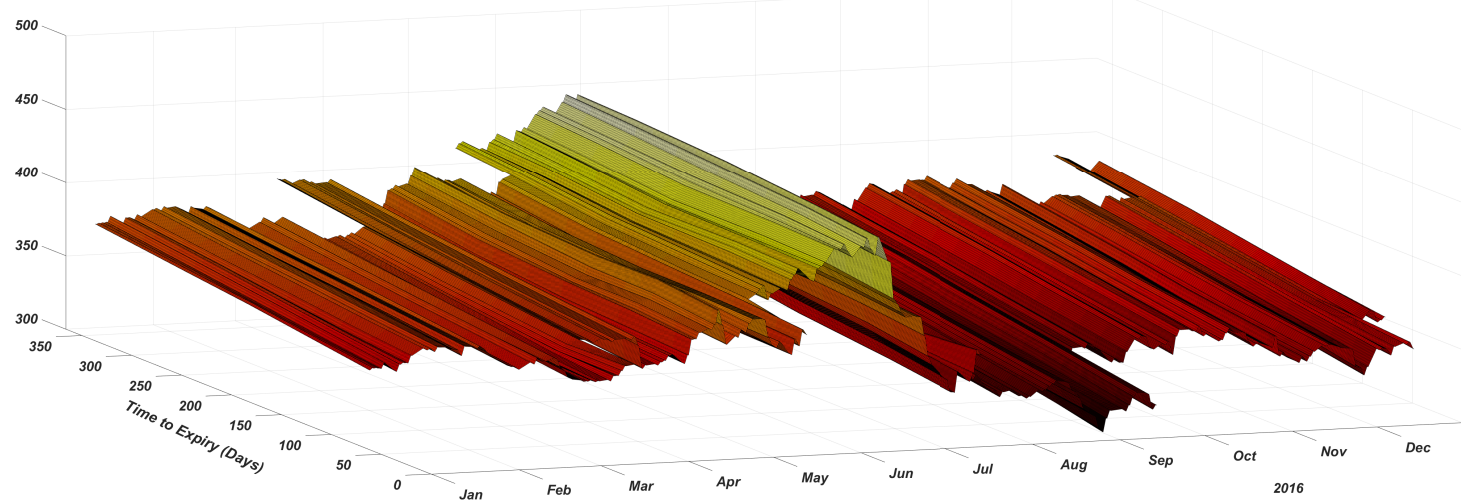

Figure 1: 252 forward curves of corn futures contracts in 2016 derived from available price information and linear interpolation.

errors. Furthermore, in such applications the choice of the smoothing or interpolation technique used should also reflect the primary goal of the analysis. For instance, it has been previously observed (see e.g. Grith et al., 2018) that under-smoothed representations of the sampled curves can be more effective when the goal is to estimate a principal component basis, although such representations may sacrifice accuracy in estimating each individual curve.

Although assuming the observed prices are errorless seems reasonable here, we have explored a number of methods following both paradigms to produce forward curves, including linear and $B$ spline interpolation and smoothing to different orders as in Kargin \& Onatski (2008) to estimate forward curves. Ultimately we decided to produce the forward curves that we study using cubic Hermite polynomial interpolation (Fritsch \& Carlson, 1980), which guarantees continuity of the first derivative. We found Hermite interpolation to be superior to $B$-spline interpolation and smoothing in this setting, both quantitatively in terms of forecasting error measures as presented in Section 4 and since smoothing splines visibly over-fit the forward curves for many commodities.

In what follows all forward curves that we consider are constructed in this way. Furthermore we assume that $t$ in $P_{i}^{(C)}(t)$ is normalized to the unit interval, so that we may think of each forward curve as a function defined on $[0,1]$. This is demonstrated in Figure 2 with comparing the forward curves obtained by cubic Hermite interpolation in three resolutions. 

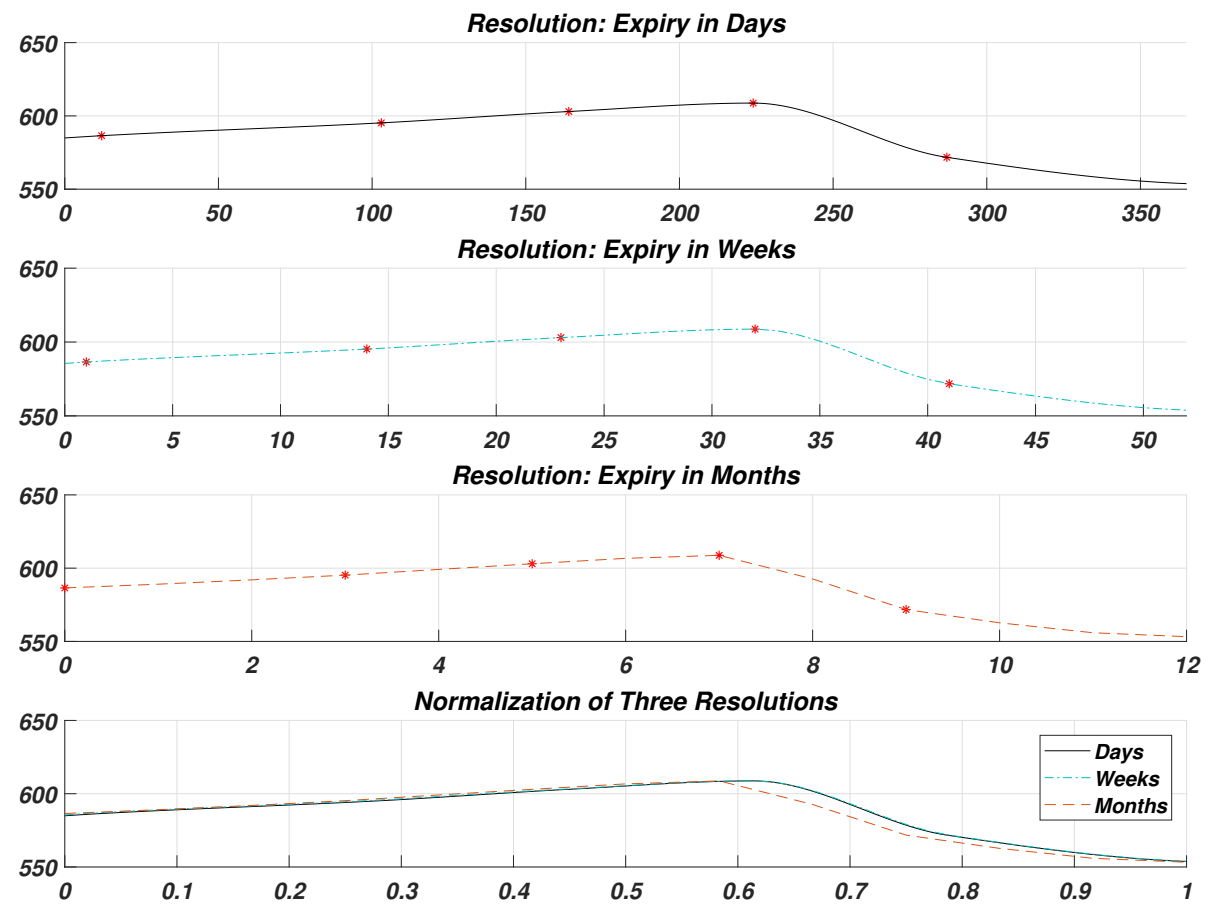

Figure 2: Comparison in three resolutions of $P_{i}^{(C)}(t)$ of corn futures contracts on December $2^{\text {nd }} 2011$. The curves are constructed by using cubic Hermite interpolation.

\section{Functional time series analysis of forward curves}

Our basic goal going forward is to evaluate the properties of the functional time series $P_{i}^{(C)}(t)$ defined from the commodity futures listed in the S\&P GSCI, and measure to what extent they are predictable using methods to forecast functional time series. As is clear in the upper panel of Figure 3 the curves $P_{i}^{(C)}(t)$ are highly non-stationary, exhibiting strong seasonality and level shifts, and this encourages one to consider transformations of $P_{i}^{(C)}(t)$ that can be studied as stationary functional time series.

Definition 3.1. Given a sequence of forward curves $P_{i}^{(C)}(t), 1 \leq i \leq N$ the log-differenced forward curves are defined by $X_{1}(t)=0$, and

$$
X_{i}(t)=100\left[\log \left(P_{i}^{(C)}(t)\right)-\log \left(P_{i-1}^{(C)}(t)\right)\right], \quad 2 \leq i \leq N .
$$

A plot of the log-differenced forward curves derived from Corn futures is given in the lower panel of Figure 3 In order to evaluate the stationarity of the log-differenced forward curves for 

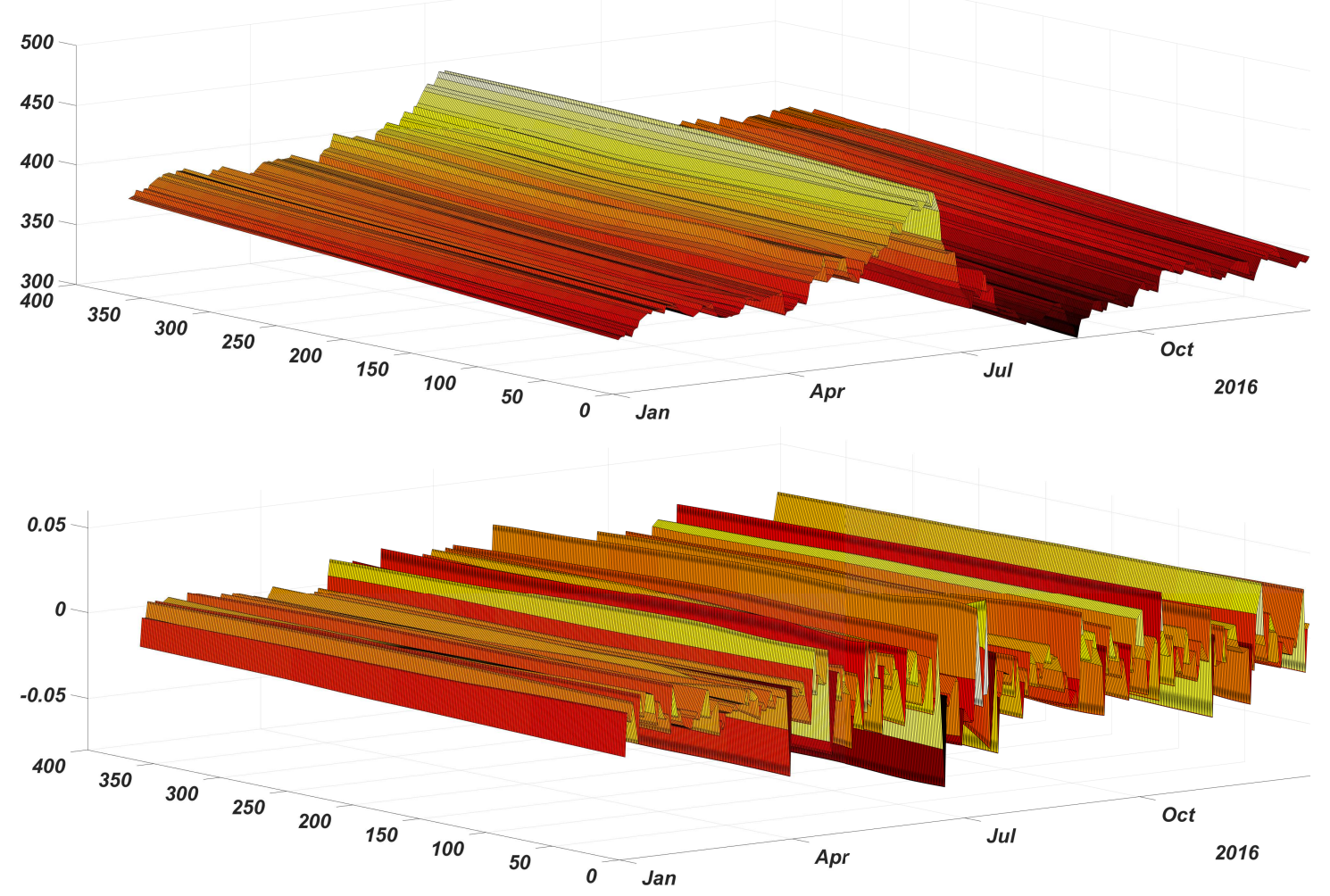

Figure 3: Upper Panel: 3D Plot of forward curves, $P_{i}^{(C)}(t)$, derived from corn futures contracts in 2016 using cubic Hermite interpolation. Lower Panel: 3D Plot of the log-differenced forward curves, $X_{i}(t)$, derived from corn futures contracts in 2016 using cubic Hermite interpolation. There are 252 curves for both panels in 2016.

each commodity listed in Table 1, we applied the KPSS test for functional time series developed in Horváth et al. (2014) to the entire sample $X_{i}(t), 1 \leq i \leq N$, which we now briefly describe. The functional analogue of the standard CUSUM process

$$
Z_{N}(x, t)=\frac{1}{\sqrt{N}}\left[\sum_{i=1}^{\lfloor N x\rfloor} X_{i}(t)-x \sum_{i=1}^{N} X_{i}(t)\right]
$$

compares the sum of the first $\lfloor N x\rfloor$ observations to the $x$ fraction of the total sum.

The functional KPSS statistic is defined as

$$
\operatorname{fKPSS}_{N}=\iint Z_{N}^{2}(x, t) d t d x
$$

Under mild weak dependence and moment conditions on the log-differenced series $X_{i}(t)$, the statistic fKPSS $_{N}$ satisfies that 


$$
\operatorname{fKPSS}_{N} \stackrel{D}{\longrightarrow} \Xi_{K P S S}, N \rightarrow \infty
$$

where $\Xi_{K P S S}$ is a random variable whose distribution can be consistently estimated from the original curves $X_{i}(t)$; see Horváth et al. (2014). The specific settings we used to perform this estimation are detailed in Appendix A Under several general departures from stationarity for the sequence $X_{i}(t)$, including change points in the mean function and unit-root type alternatives, fKPSS $_{N}$ diverges in probability to positive infinity. A $p$-value for the null hypothesis of stationarity can then be obtained as $P\left(\Xi_{K P S S}>\mathrm{fKPSS}_{N}\right)$. The $p$-values of these tests applied to the log-differenced forward curves at each temporal resolution are given in Table 3 . The results suggest that it is reasonable to assume the log-differenced curves are stationary, which provides some justification for forecasting the time series $X_{i}(t)$ using stationary functional time series models. We consider such models and forecasts below in Section 4

Assuming the series $X_{i}(t)$ is strictly stationary, we may define the autocovariance kernel of $X_{i}(t)$ at lag $h$ by $c_{h}(t, s)=\operatorname{cov}\left(X_{0}(t), X_{h}(s)\right) . c_{h}$ defines the lag $h$ autocovariance operator by $C_{h}(f)(t)=\int c_{h}(t, s) f(s) d s=\mathbb{E}\left[\left\langle X_{0}, x\right\rangle X_{h}(t)\right]$, which is instrumental in estimating the functional autoregressive models that we consider below for the purpose of forecasting. If $c_{h}(t, s)=0$ for all $h$ larger than zero, then methods for forecasting $X_{i}(t)$ based on minimizing the mean squared forecast error will reduce to estimating $X_{i}(t)$ with its mean. It is hence worthwhile to test the hypothesis

$$
\mathcal{H}_{0, K}: \quad c_{h}(t, s)=0, \text { for } h=1, \ldots, K .
$$

Tests of $\mathcal{H}_{0, K}$ are typically referred to as portmanteau tests going back to the seminal work for scalar time series of Box \& Pierce (1970). Recently a number of approaches have been proposed to test $\mathcal{H}_{0, K}$ with functional data; see Gabrys \& Kokoszka (2007), Horváth et al. (2013), and Zhang (2016). In general these tests are built under stronger assumptions than $\mathcal{H}_{0, K}$ alone, such as

$$
\mathcal{H}_{0, i i d}: \quad X_{i}(t) \text { are independent and identically distributed, }
$$

or

$$
\mathcal{H}_{0, c h}: \quad X_{i}(t)=\sigma_{i}(t) \varepsilon_{i}(t) \text { where } \varepsilon_{i}(t) \text { is a mean zero, independent }
$$

and identically distributed sequences of errors, and $\sigma_{i}^{2}(t)=g\left(\varepsilon_{i}, \varepsilon_{i-1}, \ldots\right)$. 
A test of $\mathcal{H}_{0, c h}$ is meant to account for sequences that satisfy $\mathcal{H}_{0, K}$ as approximate martingale difference sequences exhibiting conditional heteroscedasticity, as with functional versions of generalised autoregressive conditionally heteroscedastic sequences. Such functional time series models have recently been proposed in Hörmann et al. (2013) and Aue et al. (2017). Evidently $\mathcal{H}_{0, K}$ holds under both $\mathcal{H}_{0, \text { iid }}$, and $\mathcal{H}_{0, c h}$, but these stronger assumptions allow for the construction of asymptotically validated tests. Here we apply the tests of $\mathcal{H}_{0, \text { iid }}$, and $\mathcal{H}_{0, \text { ch }}$ recently proposed by Kokoszka et al. (2017). In order to describe these tests, the autocovariance kernel $c_{h}$ is estimated by

$$
\hat{c}_{h}(t, s)=\frac{1}{N} \sum_{j=1}^{N-h}\left\{X_{j}(t)-\bar{X}(t)\right\}\left\{X_{j+h}(s)-\bar{X}(s)\right\}, \quad \bar{X}(t)=\frac{1}{N} \sum_{j=1}^{N} X_{j}(t),
$$

and through these estimates we define a test statistic for $\mathcal{H}_{0, K}$ by

$$
V_{N, K}=N \sum_{h=1}^{K}\left\|\hat{c}_{h}\right\|^{2}
$$

Under $\mathcal{H}_{0, \text { iid }}$ and some additional moment conditions, it follows that

$$
V_{N, K} \stackrel{D}{\longrightarrow} \Theta_{K, i i d}, \quad N \rightarrow \infty
$$

where the distribution of $\Theta_{K, i i d}$ can be consistently estimated from the sample. Similarly under $\mathcal{H}_{0, c h}$ and some further moment and weak dependence conditions, it follows that

$$
V_{N, K} \stackrel{D}{\longrightarrow} \Theta_{K, c h}, \quad N \rightarrow \infty
$$

and again the distribution of $\Theta_{K, \text { ch }}$ can be consistently estimated. Approximate $p$-values for $\mathcal{H}_{0, i i d}$ and $\mathcal{H}_{0, c h}$ are then given by $p=P\left(\Theta_{K, \text { iid }}>V_{N, K}\right)$ and $p=P\left(\Theta_{K, \text { ch }}>V_{N, K}\right)$, respectively. These results and the necessary conditions under which they hold are detailed in Kokoszka et al. (2017), and the specific implementations of these tests that we use here are described further in Appendix A. The results of these tests applied to the log-differenced forward curves for each commodity with $K=10$ are given in Table 3 , which indicate that these curves display stronger autocovariance that is consistent with the sequence being independent and identically distributed. Most commodities reject $\mathcal{H}_{0, i i d}$ but cannot reject $\mathcal{H}_{0, \text { ch }}$, suggesting that in general the log-differenced forward curves evolve as a dependent but uncorrelated sequence of functions. However, there remains a relatively large subset of commodities (FC, LC, LH, CL, CO, HO, and NG) that reject both $\mathcal{H}_{0, \text { iid }}$ and $\mathcal{H}_{0, c h}$, indicating strong autocovariance. 
Table 3: Results of the functional KPSS test and portmanteau tests in terms of $p$-values when applied to the log-differenced forward curves for each commodity with temporal resolutions of days, weeks, and months.

\begin{tabular}{|c|c|c|c|c|c|c|c|c|c|}
\hline \multirow{2}{*}{$\begin{array}{l}\text { Resolution: } \\
------- \\
\text { Symbol/Test: }\end{array}$} & \multicolumn{3}{|c|}{ Days } & \multicolumn{3}{|c|}{ Weeks } & \multicolumn{3}{|c|}{ Months } \\
\hline & fKPSS & $\mathcal{H}_{0, \text { iid }}$ & $\mathcal{H}_{0, c h}$ & fKPSS & $\mathcal{H}_{0, \text { iid }}$ & $\mathcal{H}_{0, c h}$ & fKPSS & $\mathcal{H}_{0, \text { iid }}$ & $\mathcal{H}_{0, c h}$ \\
\hline FC & $68.3 \%$ & $0.0 \%$ & $0.0 \%$ & $67.5 \%$ & $0.0 \%$ & $0.0 \%$ & $99.3 \%$ & $0.0 \%$ & $0.0 \%$ \\
\hline LC & $77.9 \%$ & $0.0 \%$ & $0.0 \%$ & $77.5 \%$ & $0.0 \%$ & $0.1 \%$ & $100.0 \%$ & $0.0 \%$ & $0.4 \%$ \\
\hline LH & $100.0 \%$ & $0.0 \%$ & $0.0 \%$ & $100.0 \%$ & $0.0 \%$ & $0.0 \%$ & $100.0 \%$ & $0.0 \%$ & $0.0 \%$ \\
\hline $\mathrm{C}$ & $59.1 \%$ & $0.0 \%$ & $82.8 \%$ & $62.9 \%$ & $0.0 \%$ & $86.0 \%$ & $97.5 \%$ & $0.0 \%$ & $84.4 \%$ \\
\hline $\mathbf{S}$ & $62.4 \%$ & $0.0 \%$ & $76.5 \%$ & $59.8 \%$ & $0.0 \%$ & $75.2 \%$ & $99.4 \%$ & $0.0 \%$ & $72.6 \%$ \\
\hline $\mathbf{W}$ & $34.8 \%$ & $0.0 \%$ & $99.0 \%$ & $33.6 \%$ & $0.0 \%$ & $99.5 \%$ & $87.4 \%$ & $0.0 \%$ & $96.7 \%$ \\
\hline $\mathrm{CC}$ & $19.2 \%$ & $0.0 \%$ & $49.4 \%$ & $20.5 \%$ & $0.0 \%$ & $57.7 \%$ & $69.0 \%$ & $0.0 \%$ & $64.1 \%$ \\
\hline $\mathrm{KC}$ & $52.5 \%$ & $0.0 \%$ & $14.2 \%$ & $55.7 \%$ & $0.0 \%$ & $11.8 \%$ & $95.4 \%$ & $0.0 \%$ & $23.5 \%$ \\
\hline KW & $31.4 \%$ & $0.0 \%$ & $88.2 \%$ & $32.8 \%$ & $0.0 \%$ & $92.9 \%$ & $87.8 \%$ & $0.0 \%$ & $86.3 \%$ \\
\hline CT & $93.0 \%$ & $0.0 \%$ & $10.3 \%$ & $93.6 \%$ & $0.0 \%$ & $9.9 \%$ & $100.0 \%$ & $0.0 \%$ & $17.8 \%$ \\
\hline SB & $64.3 \%$ & $0.0 \%$ & $17.8 \%$ & $64.6 \%$ & $0.0 \%$ & $18.7 \%$ & $98.3 \%$ & $0.0 \%$ & $22.7 \%$ \\
\hline LA & $82.4 \%$ & $0.0 \%$ & $53.5 \%$ & $80.3 \%$ & $0.0 \%$ & $56.4 \%$ & $99.8 \%$ & $0.0 \%$ & $57.1 \%$ \\
\hline LL & $49.7 \%$ & $0.0 \%$ & $28.3 \%$ & $45.8 \%$ & $0.0 \%$ & $38.0 \%$ & $91.2 \%$ & $0.0 \%$ & $34.9 \%$ \\
\hline LP & $49.5 \%$ & $0.0 \%$ & $17.6 \%$ & $49.8 \%$ & $0.0 \%$ & $21.5 \%$ & $92.0 \%$ & $0.0 \%$ & $18.6 \%$ \\
\hline GC & $12.6 \%$ & $0.0 \%$ & $90.8 \%$ & $12.1 \%$ & $0.0 \%$ & $88.7 \%$ & $58.9 \%$ & $0.0 \%$ & $90.7 \%$ \\
\hline LN & $41.4 \%$ & $0.0 \%$ & $89.9 \%$ & $38.5 \%$ & $0.0 \%$ & $87.6 \%$ & $88.1 \%$ & $0.0 \%$ & $90.6 \%$ \\
\hline SI & $34.8 \%$ & $0.0 \%$ & $93.0 \%$ & $33.2 \%$ & $0.0 \%$ & $90.5 \%$ & $84.1 \%$ & $0.0 \%$ & $92.0 \%$ \\
\hline LX & $66.4 \%$ & $0.0 \%$ & $35.7 \%$ & $66.4 \%$ & $0.0 \%$ & $34.1 \%$ & $97.9 \%$ & $0.0 \%$ & $28.3 \%$ \\
\hline CL & $23.6 \%$ & $0.0 \%$ & $1.5 \%$ & $21.9 \%$ & $0.0 \%$ & $3.9 \%$ & $70.1 \%$ & $0.0 \%$ & $4.8 \%$ \\
\hline $\mathrm{CO}$ & $18.3 \%$ & $0.0 \%$ & $0.3 \%$ & $19.6 \%$ & $0.0 \%$ & $0.4 \%$ & $70.2 \%$ & $0.0 \%$ & $0.5 \%$ \\
\hline HO & $22.2 \%$ & $0.0 \%$ & $0.8 \%$ & $21.7 \%$ & $0.0 \%$ & $1.5 \%$ & $74.4 \%$ & $0.0 \%$ & $1.2 \%$ \\
\hline PG & $90.5 \%$ & $0.0 \%$ & $44.2 \%$ & $90.8 \%$ & $0.0 \%$ & $42.4 \%$ & $100.0 \%$ & $59.5 \%$ & $55.9 \%$ \\
\hline NG & $25.5 \%$ & $0.0 \%$ & $2.7 \%$ & $24.4 \%$ & $0.0 \%$ & $1.4 \%$ & $89.0 \%$ & $0.1 \%$ & $2.7 \%$ \\
\hline XB & $77.5 \%$ & $0.0 \%$ & $37.9 \%$ & $78.5 \%$ & $0.0 \%$ & $34.6 \%$ & $99.9 \%$ & $26.4 \%$ & $52.1 \%$ \\
\hline
\end{tabular}

Note: the parameter $K=10$ in the portmanteau tests. Red bold values indicate that they are less than $5 \%$. 


\section{A comparison of forecasting methods for forward curves}

The fact that quite a large number of commodities have log-differenced forward curves exhibiting strong serial correlation suggests that they might be predictable using linear forecasting techniques for curves. In this section we develop several approaches for forecasting the full forward curves, and provide a comparative study of each method for one step (one-day) ahead forecasting. The basic theory of linear functional time series forecasting was put forward in Bosq (2000), with the most widely employed method being functional autoregression. The functional autoregressive model of order $\mathcal{K}$ takes the form

$$
\operatorname{FAR}(\mathcal{K}): X_{n}(t)=\Psi_{1}\left(X_{n-1}\right)(t)+\cdots+\Psi_{\mathcal{K}}\left(X_{n-\mathcal{K}}\right)(t)+\varepsilon_{n}(t),
$$

where $\Psi_{i} 1 \leq i \leq \mathcal{K}$ is a kernel integral operator with kernel $\psi_{i}(t, s)$, i.e. $\Psi_{i}(f)(t)=\int \psi_{i}(t, s) f(s) d s$. Given the evident seasonal patterns in forward curves (Routledge et al. 2000, Sørensen, 2002, Borovkova \& Geman, 2006), it is also reasonable to consider functional autoregressive models including lags of the series $X_{i}(t)$ corresponding to the clear seasonal variations in the price, for instance one week, month, quarter, etc.. We define the functional seasonal autoregressive model as

FSAR: $X_{n}(t)=\Psi_{\ell, 1}\left(X_{n-\ell_{1}}\right)(t)+\cdots+\Psi_{\ell, k}\left(X_{n-\ell_{k}}\right)(t)+\varepsilon_{n}(t)$,

where the $\Psi_{\ell, i} 1 \leq i \leq k$ are kernel integral operators with kernels $\psi_{\ell, i}(t, s)$, and $\ell_{1}, \ldots, \ell_{k}$ are specified lags.

These models can be estimated in a number of ways, and we consider two distinct methods. First we present an FPCA based estimator of $\Psi_{1}$ in the FAR(1) model, and similar estimators can be defined for the $\operatorname{FAR}(\mathcal{K})$ and FSAR models, which we develop in Appendix $\mathrm{A}$. Following the principle of least squares, a natural estimator of $\Psi_{1}$ would be given by $\hat{\Psi}_{1}=\hat{C}_{1} \hat{C}_{0}^{-1}$, where the functional covariance $C_{0}$ and $C_{1}$ are the lag zero and one autocovariance operators of the sequence $X_{i}(t)$. The empirical covariance and empirical lag-1 autocovariance operator can be estimated by

$$
\begin{aligned}
& \hat{C}_{0}(x)(t)=\frac{1}{N} \sum_{j=1}^{N}\left\langle X_{j}-\bar{X}_{1}, x\right\rangle\left[X_{j}(t)-\bar{X}(t)\right], \\
& \hat{C}_{1}(x)(t)=\frac{1}{N} \sum_{k=1}^{N-1}\left\langle X_{k}-\bar{X}_{1}, x\right\rangle\left[X_{k+1}(t)-\bar{X}(t)\right],
\end{aligned}
$$

which are each kernel integral operators with kernel $\hat{c}_{0}(t, s)$ and $\hat{c}_{1}(t, s)$, respectively. As discussed in Horváth \& Kokoszka (2012), the inverse of the covariance operator $C_{0}$ is not bounded, which 
can be handled by projecting $C_{0}$ onto the subspace generated by the $p$ leading functional principal components. In the literature of functional data analysis, the choice of $p$ has been considered extensively, but no theoretical results regarding an "optimal" choice for forecasting purposes have been established. Usually, $p$ is chosen with the objective that the largest $p$ principal components explain a specified, high percentage of the "variance" of the observations (see e.g., Ramsay \& Silverman, 2002), such as $90 \%, 95 \%$ or $99 \%$. When the main goal is forecasting, cross-validation may be used to select $p$ in order to avoid overfitting (e.g., Kargin \& Onatski, 2008). Denote the empirical principal components (PCs) of the functional observations $X_{i}(t)$ as, $\hat{\nu}_{j}, j=1,2,3 \ldots, p$. The inverse operator $C_{0}^{-1}$ using the first $p$ PCs is defined as

$$
\hat{\Gamma}_{p}(x)(t)=\sum_{j=1}^{p} \hat{\lambda}_{j}^{-1}\left\langle x, \hat{\nu}_{j}\right\rangle \hat{\nu}_{j}(t)
$$

from which we obtain the estimator for $\Psi_{1, p}$

$$
\begin{aligned}
\hat{\Psi}_{1, p}(x) & =\hat{C}_{1} \hat{\Gamma}_{p}(x) \\
& =\hat{C}_{1}\left(\sum_{j=1}^{p} \hat{\lambda}_{j}^{-1}\left\langle x, \hat{\nu}_{j}\right\rangle \hat{\nu}_{j}\right) \\
& =\frac{1}{N-1} \sum_{k=1}^{N-1}\left\langle X_{k}, \sum_{j=1}^{p} \hat{\lambda}_{j}^{-1}\left\langle x, \hat{\nu}_{j}\right\rangle \hat{\nu}_{j}\right\rangle X_{k+1} \\
& =\frac{1}{N-1} \sum_{k=1}^{N-1} \sum_{j=1}^{p} \hat{\lambda}_{j}^{-1}\left\langle x, \hat{\nu}_{j}\right\rangle\left\langle X_{k}, \hat{\nu}_{j}\right\rangle X_{k+1} .
\end{aligned}
$$

If a smoothing procedure is applied to $X_{k+1}(t) \approx \sum_{i=1}^{p}\left\langle X_{k+1}, \hat{\nu}_{i}\right\rangle \hat{\nu}_{i}(t)$, the estimator further becomes

$$
\hat{\Psi}_{1, p}(x)=\frac{1}{N-1} \sum_{k=1}^{N-1} \sum_{j=1}^{p} \sum_{i=1}^{p} \hat{\lambda}_{j}^{-1}\left\langle x, \hat{\nu}_{j}\right\rangle\left\langle X_{k}, \hat{\nu}_{j}\right\rangle\left\langle X_{k+1}, \hat{\nu}_{i}\right\rangle \hat{\nu}_{i} .
$$

The estimated kernel for the operator in equation 5 is

$$
\hat{\psi}_{1, p}(t, s)=\frac{1}{N-1} \sum_{k=1}^{N-1} \sum_{j=1}^{p} \sum_{i=1}^{p} \hat{\lambda}_{j}^{-1}\left\langle X_{k}, \hat{\nu}_{j}\right\rangle\left\langle X_{k+1}, \hat{\nu}_{i}\right\rangle \hat{\nu}_{j}(s) \hat{\nu}_{i}(t)
$$

Using the estimated kernel, we can make 1-step predictions as

$$
\begin{aligned}
\hat{X}_{n+1}(t) & =\int \hat{\psi}_{1, p}(t, s) X_{n}(s) d s \\
& =\sum_{j=1}^{p}\left(\sum_{i=1}^{p} \hat{\psi}_{1, p}\left\langle X_{n}, \hat{\nu}_{i}\right\rangle\right) \hat{\nu}_{j}(t)
\end{aligned}
$$


An alternative approach to estimating the FAR(1) model is to use the method of predictive factors, as proposed in Kargin \& Onatski (2008). Effectively, this method aims to perform the dimension reduction step in estimating $\Psi_{1}$ in such a way that it minimizes the one step prediction error. It can be described as follows. The method aims to find an operator $A$ that minimizes the prediction error

$$
\min _{A \in \mathcal{R}_{p}}\left\{\mathbb{E}\left\|X_{n+1}-A\left(X_{n}\right)\right\|^{2}\right\}
$$

where $R_{p}$ is the set of all rank $p$ operators mapping $L^{2}[0,1]$ into a subspace of dimension $p$. It was shown in Kargin \& Onatski (2008) that this minimization can be approximately achieved using an operator of the form

$$
\Psi_{1, p}(y) \approx \sum_{i=1}^{p}\left\langle y, b_{i}\right\rangle C_{1}\left(b_{i}\right), \quad b_{i}=C_{0}^{-1 / 2}\left(x_{i}\right),
$$

where the processes $\left.\left\{\left\langle y, b_{i}\right\rangle, i=1, \ldots, p\right)\right\}$ are termed the predictive factors, and the functions $\left.\left\{C_{1}\left(b_{i}\right), i=1, \ldots, p\right)\right\}$ are termed the corresponding predictive loadings, which are the most relevant "directions" for one step ahead mean squared norm prediction. Again since $C_{0}^{-1 / 2}$ is not bounded, Kargin \& Onatski (2008) proposed the following regularized estimator. With

$$
\hat{\Phi}_{\alpha, 1}=\hat{C}_{0, \alpha}^{-1 / 2} \hat{C}_{1}^{T} \hat{C}_{1} \hat{C}_{0, \alpha}^{-1 / 2}, \quad \hat{C}_{0, \alpha}=\hat{C}_{0}+\alpha I,
$$

the operator $\Psi_{1, p}$ is estimated by

$$
\hat{\Psi}_{\alpha, 1, p}(x)(t)=\sum_{i=1}^{p}\left\langle x, \hat{b}_{\alpha, i}\right\rangle \hat{C}_{1}\left(\hat{b}_{\alpha, i}\right)(t), \quad \hat{b}_{\alpha, i}=\hat{C}_{0, \alpha}^{-1 / 2}\left(\hat{x}_{\alpha, i}\right)
$$

where $\alpha \in \mathbb{R}^{+}$is a regularisation parameter, $I$ is the identity operator, and $\hat{x}_{\alpha, 1}, \ldots, \hat{x}_{\alpha, k}$ are the eigenfunctions of $\hat{\Phi}_{\alpha, 1}$. Then the 1-step prediction is determined by

$$
\hat{X}_{n+1}(t)=\hat{\Psi}_{\alpha, 1, p}\left(X_{n}\right)(t) \text {. }
$$

We follow Kargin \& Onatski (2008) to select the number of predictive factors and the regularisation parameter by cross validation. We also implemented the technique of predictive factors with additional lags added, and found that these models tended to perform similarly to the single lag model, but at a much higher computational cost due to applying cross validation to select optimized values for multiple predictive factor regularization parameters.

It is worthwhile at this point to describe the primary similarities and differences between the FPCA and predictive factors estimation procedures. Although the motivation for the predictive 
factors approach derives from finding a low rank linear operator to minimize the one step prediction error in (7), and hence might appear more suitable for the forecasting problem at hand, since the FAR(1) framework is considered in both cases they each ultimately aim to estimate the same operator $C_{1} C_{0}^{-1}$. Fundamentally then the differences derive from how the operator $C_{0}^{-1}$ is estimated. In the FPCA case it is essentially assumed that the observed data are contained in the linear span of a finite collection of principal components in order that $C_{0}^{-1}$ is bounded. The predictive factors approach implements a Tychonoff regularization that is tuned with cross validation to estimate $C_{0}^{-1}$. As such, one may understand the difference in performance of these methods in terms of the relative performance in prediction problems of principal component analysis versus regularisation techniques. It has been argued empirically that regularisation techniques tend to perform better in such cases, see Hall \& Horowitz (2007) for a discussion in the setting of functional data, and we see below that the predictive factors technique of Kargin \& Onatski (2008) tends in general to outperform the FPCA based methods.

\subsection{Application to forecasting forward curves}

We now provide the results of a comparative study of the above forecasting methods applied to forecasting forward curves. Since the functional forecasting models are based on the logdifferenced forward curves, we used a given period of data to fit each of the proposed functional forecasting models and then to forecast the log-differenced forward curve $\hat{X}_{n+1}(t)$ by (6) or (8), which from (1) leads to the forecasted curve at trading day $n+1$ as $\hat{P}_{n+1}^{(C)}(t)=\exp \left\{\left[\hat{X}_{n+1}(t)+\right.\right.$ $\left.\left.100 \log \left(P_{n}^{(C)}(t)\right)\right] / 100\right\}$. The specific model 5 that we considered for the log-differenced forward curves are:

- $\operatorname{FAR}(1)$ : Functional autoregressive process of order one

- $\boldsymbol{F A R ( 2 ) : ~ F u n c t i o n a l ~ a u t o r e g r e s s i v e ~ p r o c e s s ~ w i t h ~ l a g s ~}[1,2]$.

- $\operatorname{FAR}(4)$ : Functional autoregressive process with lags $[1,2,3,4]$.

- FSAR: Functional seasonal autoregressive with lags $[1,5,21,63]$.

- FAR(1)-PF: Functional autoregressive process of order one estimated using predictive factors.

\footnotetext{
${ }^{5} \operatorname{FAR}(\mathcal{K})$ has lags at $1,2, \ldots \mathcal{K}$, while FSAR has selected lags at $\ell_{1}, \ldots, \ell_{k}$ due to seasonality.
} 
We also compared these to forecasts $\hat{\mathbf{P}}_{i}$ of the multivariate vector $\mathbf{P}_{i}=\left(P_{i}\left(t_{i, 1}\right), \ldots, P_{i}\left(t_{1, J}\right)\right)^{\top}$ using the method of Diebold \& Li (2006), as well as naïve forecasts for the purpose of comparison. The benchmarks we compared to then were:

- DL: The method of Diebold \& Li (2006), which is based on the dynamic Nelson-Siegel model with three factors of level, slope and curvature. We used the MATLAB implementation given in the Financial Instruments Toolbox of The MathWorks, Inc. (2019) applied to $\mathbf{P}_{i}$.

- naïve: Use current forward curve to predict the forward curve in the next day, $\hat{P}_{n+1}^{(C)}(t)=$ $P_{n}^{(C)}(t)$.

In order to measure the forecast error, we considered the following four measures:

$$
\text { Functional Error: } \operatorname{Err}_{f}=\left(\frac{1}{N} \sum_{i=1}^{N} \int_{t_{i, 1}}^{t_{i, J}}\left(\hat{P}_{i}^{(C)}(t)-P_{i}^{(C)}(t)\right)^{2} d t\right)^{1 / 2}
$$

Relative Functional Error: $\operatorname{RErr}_{f}=\left(\frac{1}{N} \sum_{i=1}^{N} \frac{\int_{t_{i, 1}}^{t_{i, J}}\left(\hat{P}_{i}^{(C)}(t)-P_{i}^{(C)}(t)\right)^{2} d t}{\left\|P_{i}^{(C)}(t)\right\|^{2}}\right)^{1 / 2}$

$$
\text { Multivariate Error: } \operatorname{Err}_{m}=\left(\frac{1}{N} \sum_{i=1}^{N} \sum_{j=1}^{J}\left(\hat{P}_{i}\left(t_{i, j}\right)-P_{i}\left(t_{i, j}\right)\right)^{2}\right)^{1 / 2}
$$

Relative Multivariate Error: $R E r r_{m}=\left(\frac{1}{N} \sum_{i=1}^{N} \sum_{j=1}^{J} \frac{\left(\hat{P}_{i}\left(t_{i, j}\right)-P_{i}\left(t_{i, j}\right)\right)^{2}}{P_{i}\left(t_{i, j}\right)^{2}}\right)^{1 / 2}$

where $P_{i}\left(t_{i, j}\right)$ denotes the raw prices that $t_{i, j}$ are the time points at which price information is available, and $\hat{P}_{i}\left(t_{i, j}\right)$ is identified by extracting the values at the certain time points $t_{i, j}$ from the forecasted functional curve $\hat{P}_{i}^{(C)}(t)$.

Before examining the performance of the above methods, an important consideration in each of the proposed forecasting procedures is the selection of various hyperparameters, including the number of the principal components in FAR and FSAR, the number of the predictive factors and the value of the regularization parameter $\alpha$ in PF, and the parameter $\lambda$ in the method of Diebold $\& \mathrm{Li}(2006)$. To find the optimized values of hyperparameters, we performed times series cross validation (TSCV); see for example Hart (1994) for a description. Specifically we split the whole data set $D_{n}(t)=\left\{P_{n}(t), P_{n}^{(C)}(t), X_{n}(t)\right\}, n=1, \ldots, N$ into three segments of equal length 6 , which

\footnotetext{
${ }^{6}$ The specific start date and end date of three segments for all commodity futures are reported in Table 11
} 
we refer to as training data $\left\{D_{1}(t), \ldots, D_{\lfloor N / 3\rfloor}(t)\right\}$, validation data $\left\{D_{\lfloor N / 3\rfloor+1}(t), \ldots, D_{\lfloor 2 N / 3\rfloor}(t)\right\}$, and test data $\left\{D_{\lfloor 2 N / 3\rfloor+1}(t), \ldots, D_{N}(t)\right\}$. We use an expanding window starting with the training data to predict the data one step ahead in the validation set. The hyperparameters are selected to minimize the total error in predicting each curve in the validation set7 Selected number of the principal components and the predictive factors are typically ranging between 1 and 5 . After obtaining the optimized hyperparameters, we are able to examine the forecasting performance in the test period. Similar to the TSCV procedure, we conducted subsequent forecasts using an expanding window schem 8 , i.e. the model was re-estimated with all data up to date $n$ in order to produce the forecast for the next observation at date $n+1$. The forecast of nine randomly selected Corn forward curves in the test period are displayed in Figure 4
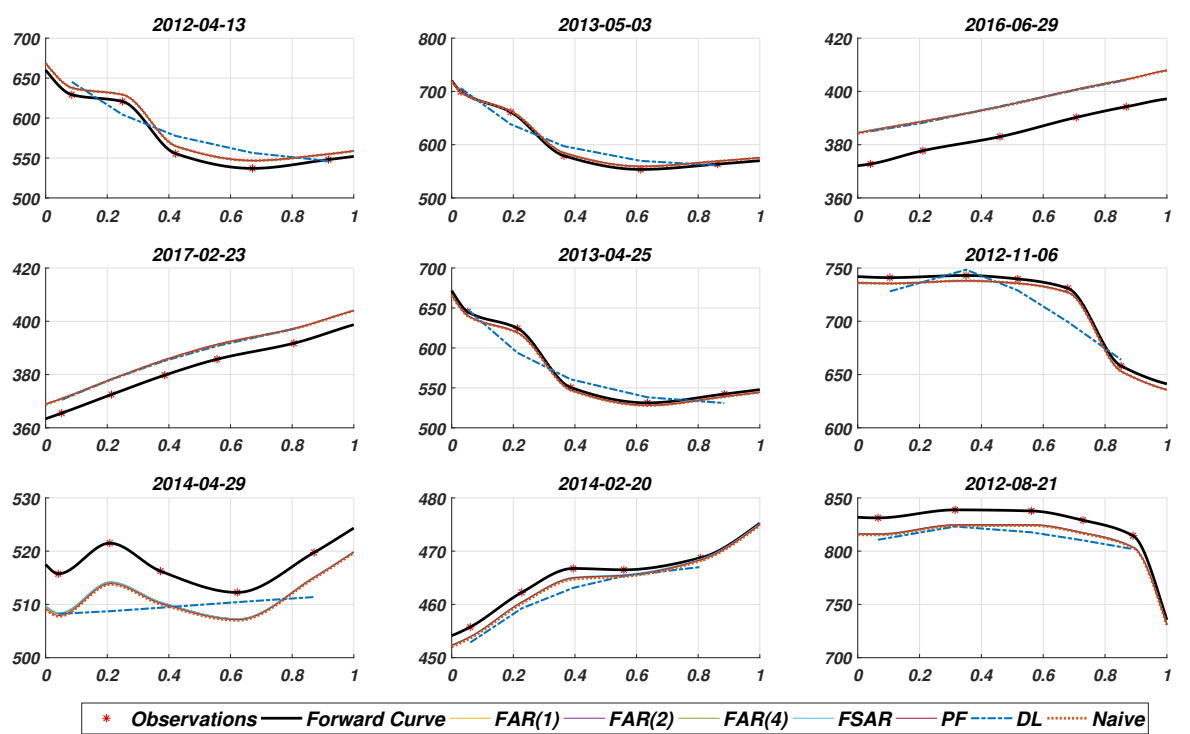

Figure 4: Forecasts from different models using daily resolution corn futures forward curves from nine randomly selected dates.

\footnotetext{
${ }^{7}$ The error measure for a one-step-ahead predictor with a given set of hyperparameters is calculated in the following way: 1) fit the model to the data $\left\{D_{1}(t), \cdots, D_{n}(t)\right\}$ and make a one-step-ahead prediction for the forward curve; 2) repeat Step 1 for $n=\lfloor N / 3\rfloor+1, \ldots,\lfloor 2 N / 3\rfloor$, where $\lfloor N / 3\rfloor+1$ and $\lfloor 2 N / 3\rfloor$ are the start date and the end date in the validation period, respectively; 3 ) compute the error measure over the validation period.

${ }^{8}$ To be specific, the forecasting for the test period is conducted by the following procedure: $i$ ) using the optimized value of hyperparameters, fit the model to the data $\left\{D_{1}(t), \ldots, D_{n}(t)\right\}$ and make a one-step-ahead prediction for the forward curve; ii) repeat Step $i$ for $n=\lfloor 2 N / 3\rfloor+1, \ldots, N$, where $\lfloor 2 N / 3\rfloor+1$ and $N$ are the start date and the end date in the test period, respectively; iii) Compute the error measure over the test period.
} 
We evaluated each of these measures taken both over the validation period as well as over the test data to measure their predictive power. First, we considered how the choice of the temporal resolution of the forward curves affected forecasts. Table 4 shows the average relative forecasting error over all commodities for each model considered for the daily, weekly, and monthly resolution curves. From this it is clear that considering the daily resolution substantially improves forecasting for the functional methods. By the measure of relative multivariate error on the average of all commodities, the functional forecasting methods outperform the multivariate method of DL in all three resolutions.

The prediction errors for each model and across commodities in both validation and test periods are given in Tables 5 and 6 when the forward curves are constructed at the daily resolution; similar tables at the weekly and monthly resolution are given in Appendix B. Across all commodities the functional methods tended to significantly outperform the multivariate forecasting approach of Diebold \& Li (2006). When comparing error rates in the validation period, PF produces the best forecasting performance for most commodities according to the multivariate error. Naïve method also have smallest functional error measure for several commodities. FAR methods can occasionally outperform the PF and the naïve methods. In terms of prediction error in the testing period, in many cases the naïve forecast was superior to the other forecasting methods considered, which agrees with the results of the portmanteau tests in Table 3 . According to our test results, most of those forward curves evolve as dependent but uncorrelated sequences of functions. However, for some commodities (FC, LH, CL, and NG) the method of predictive factors was able to beat the naïve forecast in the test period regardless of which error measure is used. Some of these commodities interestingly coincides with those commodities whose logdifferenced forward curves were measured to be predictable by the portmanteau tests. In these cases the multivariate approach of Diebold \& Li (2006) was still worse than the naïve forecast in the relative forecasting performance.

The relative superiority of the PF method compared to the principal component based methods were to some extent expected. In the multivariate setting, regularized estimators are known to have good out-of-sample forecasting performance relative to least square estimators (e.g. Bernardini \& Cubadda, 2015). Also, as is investigated and discussed in Bai \& Ng (2019), such regularized principal component estimators are more robust when compared to standard PCA to large model errors, which may be thought to arise in this application from "spikes" in the curves caused by expiring contracts and the rollover effect. The performance of the multivariate procedure of Diebold \& Li (2006) we believe can be explained by its reliance on the three factors 
Table 4: Average relative forecasting error across commodities for daily, weekly, and monthly resolution forward curves.

\begin{tabular}{clcccccc}
\hline \hline \multirow{2}{*}{ Error Measure } & & \multicolumn{2}{c}{ Validation Period } & \multicolumn{3}{c}{ Test Period } \\
& Model $\backslash$ Resolution & day & week & month & day & week & month \\
\hline & FAR(1) & $1.9039 \%$ & $1.9079 \%$ & $1.9410 \%$ & $1.4484 \%$ & $1.4540 \%$ & $1.4916 \%$ \\
& FAR(2) & $1.9044 \%$ & $1.9085 \%$ & $1.9415 \%$ & $1.4486 \%$ & $1.4543 \%$ & $1.4921 \%$ \\
Relative Functional & FAR(4) & $1.9066 \%$ & $1.9106 \%$ & $1.9433 \%$ & $1.4495 \%$ & $1.4552 \%$ & $1.4929 \%$ \\
Error & FSAR & $1.9057 \%$ & $1.9097 \%$ & $1.9426 \%$ & $1.4502 \%$ & $1.4557 \%$ & $1.4929 \%$ \\
& PF & $1.9007 \%$ & $1.9049 \%$ & $1.9384 \%$ & $1.4436 \%$ & $1.4493 \%$ & $1.4877 \%$ \\
& Naïve & $1.9005 \%$ & $1.9045 \%$ & $1.9376 \%$ & $1.4433 \%$ & $1.4489 \%$ & $1.4871 \%$ \\
\hline \multirow{3}{*}{ Relative Multivariate } & FSAR & $5.4790 \%$ & $5.4939 \%$ & $5.5973 \%$ & $4.1778 \%$ & $4.1944 \%$ & $4.3203 \%$ \\
Error & FAR(1) & $5.4805 \%$ & $5.4959 \%$ & $5.5985 \%$ & $4.1783 \%$ & $4.1950 \%$ & $4.3216 \%$ \\
& FAR(2) & $5.4868 \%$ & $5.5018 \%$ & $5.6041 \%$ & $4.1800 \%$ & $4.1970 \%$ & $4.3235 \%$ \\
& FAR(4) & $5.4841 \%$ & $5.4989 \%$ & $5.6020 \%$ & $4.1837 \%$ & $4.1998 \%$ & $4.3245 \%$ \\
& Naïve & $5.4699 \%$ & $5.4852 \%$ & $5.5893 \%$ & $4.1622 \%$ & $4.1790 \%$ & $4.3078 \%$ \\
& DL & $5.4685 \%$ & $5.4836 \%$ & $5.5870 \%$ & $4.1618 \%$ & $4.1784 \%$ & $4.3067 \%$ \\
\hline \hline
\end{tabular}

Note: red bold values indicate that they are smallest in the three resolutions. The multivariate method of DL has the same performance for the three resolutions.

of level, slope, and curvature. Although the three factors could explain well for the term structure of government bond yields, it appears to not be sufficient for the more complicated shape of forward curves derived from commodity futures. By comparison, the principal components and predictive factors appear to provide more flexibility in describing the variety of underlying shapes of the forward curve over time.

\section{Conclusion}

We provide a thorough analysis using new tools in functional time series analysis of forward curves derived from a number of commodity futures listed in the S\&P GSCI. We considered how one can interpolate the raw contract information to form full forward curves using cubic Hermite polynomials, and studied how constructing the curves using different temporal units to measure the time to expiry of the contract affects subsequent analysis of the curves. Regardless of the resolution used to measure the time to expiry, forward curves themselves are apparently nonstationary, however the log-differenced forward curves do appear to be stationary as measured by a functional analog of the KPSS test. Portmanteau tests indicate that for most commodities the amount of autocovariance observed in the sequence of curves is more than one would expect for a strong white noise sequence of curves, but is in accordance with what might be observed from 
Table 5: Forecasting performance evaluated using functional and multivariate error measures $\operatorname{Err}_{f}$ and $\operatorname{Err}_{m}$ for commodity futures forward curves at a daily resolution.

\begin{tabular}{|c|c|c|c|c|c|c|c|c|c|c|c|c|c|}
\hline \multicolumn{14}{|c|}{ Validation Period } \\
\hline \multirow[b]{2}{*}{ Symbol } & \multicolumn{6}{|c|}{ Functional Error } & \multicolumn{7}{|c|}{ Multivariate Error } \\
\hline & $\operatorname{FAR}(1)$ & FAR(2) & $\operatorname{FAR}(4)$ & FSAR & PF & Naïve & $\operatorname{FAR}(1)$ & FAR(2) & FAR(4) & FSAR & PF & DL & Naïve \\
\hline FC & 0.795 & 0.794 & 0.794 & 0.795 & 0.788 & 0.793 & 2.324 & 2.324 & 2.322 & 2.325 & 2.307 & 2.612 & 2.321 \\
\hline LC & 0.730 & 0.730 & 0.731 & 0.731 & 0.730 & 0.730 & 1.887 & 1.888 & 1.890 & 1.890 & 1.886 & 3.339 & 1.886 \\
\hline LH & 0.819 & 0.819 & 0.819 & 0.818 & 0.816 & 0.819 & 2.305 & 2.304 & 2.305 & 2.303 & 2.302 & 5.362 & 2.305 \\
\hline C & 9.231 & 9.226 & 9.232 & 9.243 & 9.214 & 9.217 & 22.000 & 21.993 & 22.007 & 22.033 & 21.958 & 25.480 & 21.968 \\
\hline $\mathbf{s}$ & 17.228 & 17.218 & 17.242 & 17.265 & 17.223 & 17.219 & 47.640 & 47.613 & 47.679 & 47.733 & 47.622 & 53.755 & 47.612 \\
\hline $\mathbf{W}$ & 15.161 & 15.139 & 15.147 & 15.155 & 15.131 & 15.130 & 36.009 & 35.958 & 35.985 & 36.002 & 35.932 & 42.133 & 35.937 \\
\hline $\mathrm{CC}$ & 44.948 & 44.970 & 44.998 & 45.049 & 44.961 & 44.945 & 106.597 & 106.671 & 106.749 & 106.862 & 106.640 & 106.966 & 106.600 \\
\hline KC & 2.754 & 2.759 & 2.761 & 2.757 & 2.758 & 2.758 & 6.513 & 6.526 & 6.531 & 6.521 & 6.523 & 6.605 & 6.523 \\
\hline KW & 14.682 & 14.679 & 14.680 & 14.653 & 14.596 & 14.620 & 34.814 & 34.813 & 34.819 & 34.745 & 34.623 & 40.150 & 34.681 \\
\hline CT & 1.611 & 1.611 & 1.608 & 1.612 & 1.609 & 1.610 & 3.844 & 3.844 & 3.836 & 3.846 & 3.838 & 4.616 & 3.841 \\
\hline SB & 0.386 & 0.387 & 0.388 & 0.387 & 0.384 & 0.386 & 0.877 & 0.879 & 0.882 & 0.878 & 0.872 & 4.680 & 0.876 \\
\hline LA & 38.228 & 38.234 & 38.246 & 38.253 & 38.162 & 38.186 & 129.797 & 129.822 & 129.865 & 129.882 & 129.568 & 139.121 & 129.650 \\
\hline LL & 56.855 & 56.831 & 56.803 & 56.888 & 56.694 & 56.694 & 193.098 & 193.008 & 192.900 & 193.222 & 192.539 & 196.365 & 192.561 \\
\hline LP & 144.231 & 144.468 & 144.723 & 145.264 & 143.749 & 143.807 & 490.338 & 491.202 & 492.051 & 493.945 & 488.790 & 567.637 & 488.991 \\
\hline GC & 13.229 & 13.233 & 13.239 & 13.228 & 13.217 & 13.231 & 33.811 & 33.822 & 33.838 & 33.811 & 33.780 & 34.854 & 33.817 \\
\hline LN & 638.153 & 638.264 & 638.527 & 638.395 & 638.796 & 638.275 & 2164.044 & 2164.318 & 2164.992 & 2164.800 & 2166.208 & 2196.155 & 2164.741 \\
\hline SI & 0.515 & 0.516 & 0.516 & 0.515 & 0.515 & 0.515 & 1.202 & 1.202 & 1.202 & 1.202 & 1.201 & 1.253 & 1.200 \\
\hline$\underline{\mathbf{L X}}$ & $\begin{array}{r}61.073 \\
-\ldots-\ldots\end{array}$ & $\begin{array}{r}61.072 \\
--.-\end{array}$ & 61.198 & 61.146 & 61.132 & 61.089 & 206.371 & 206.357 & 206.773 & 206.623 & 206.571 & 211.740 & 206.451 \\
\hline$\overline{C L}^{-}$ & 1.681 & 1.681 & 1.684 & 1.682 & 1.679 & 1.678 & 5.948 & 5.949 & 5.959 & 5.951 & 5.943 & 6.183 & 5.939 \\
\hline $\mathrm{CO}$ & 1.646 & 1.646 & 1.648 & 1.650 & 1.642 & 1.642 & 5.824 & 5.824 & 5.833 & 5.838 & 5.811 & 6.083 & 5.811 \\
\hline HO & 4.407 & 4.410 & 4.409 & 4.402 & 4.401 & 4.398 & 15.616 & 15.626 & 15.624 & 15.599 & 15.597 & 16.627 & 15.588 \\
\hline PG & 3.638 & 3.641 & 3.650 & 3.651 & 3.640 & 3.641 & 13.142 & 13.150 & 13.184 & 13.189 & 13.149 & 21.254 & 13.154 \\
\hline NG & 0.160 & 0.160 & 0.161 & 0.160 & 0.160 & 0.160 & 0.573 & 0.572 & 0.573 & 0.573 & 0.571 & 1.281 & 0.570 \\
\hline $\mathrm{XB}$ & 3.725 & 3.729 & 3.732 & 3.725 & 3.730 & 3.729 & 12.776 & 12.791 & 12.799 & 12.781 & 12.797 & 18.342 & 12.792 \\
\hline
\end{tabular}

\begin{tabular}{|c|c|c|c|c|c|c|c|c|c|c|c|c|c|}
\hline \multirow[b]{2}{*}{ Symbol } & \multicolumn{6}{|c|}{ Functional Error } & \multicolumn{7}{|c|}{ Multivariate Error } \\
\hline & FAR(1) & FAR $(2)$ & FAR(4) & FSAR & PF & Naïve & FAR(1) & FAR(2) & FAR(4) & FSAR & PF & DL & Naïve \\
\hline FC & 1.462 & 1.464 & 1.461 & 1.464 & 1.442 & 1.447 & 4.251 & 4.256 & 4.250 & 4.260 & 4.199 & 4.753 & 4.211 \\
\hline LC & 1.034 & 1.035 & 1.034 & 1.033 & 1.032 & 1.031 & 2.674 & 2.678 & 2.672 & 2.671 & 2.666 & 4.609 & 2.667 \\
\hline LH & 0.839 & 0.839 & 0.839 & 0.839 & 0.836 & 0.839 & 2.390 & 2.391 & 2.390 & 2.389 & 2.382 & 6.536 & 2.390 \\
\hline C & 6.852 & 6.853 & 6.857 & 6.884 & 6.842 & 6.836 & 16.323 & 16.323 & 16.335 & 16.393 & 16.295 & 22.825 & 16.287 \\
\hline $\mathrm{s}$ & 13.395 & 13.433 & 13.393 & 13.444 & 13.393 & 13.382 & 37.189 & 37.307 & 37.176 & 37.321 & 37.173 & 51.402 & 37.145 \\
\hline w & 8.931 & 8.931 & 8.926 & 8.954 & 8.939 & 8.929 & 21.140 & 21.139 & 21.127 & 21.195 & 21.158 & 22.098 & 21.136 \\
\hline $\mathrm{CC}$ & 34.495 & 34.494 & 34.592 & 34.495 & 34.493 & 34.467 & 82.197 & 82.196 & 82.437 & 82.208 & 82.195 & 82.303 & 82.135 \\
\hline $\mathrm{KC}$ & 3.047 & 3.053 & 3.059 & 3.046 & 3.042 & 3.040 & 7.171 & 7.186 & 7.200 & 7.170 & 7.159 & 7.165 & 7.156 \\
\hline KW & 9.064 & 9.053 & 9.063 & 9.089 & 9.049 & 9.046 & 21.395 & 21.365 & 21.390 & 21.455 & 21.355 & 22.620 & 21.347 \\
\hline CT & 0.845 & 0.846 & 0.852 & 0.845 & 0.841 & 0.843 & 2.058 & 2.061 & 2.075 & 2.060 & 2.051 & 2.326 & 2.055 \\
\hline SB & 0.230 & 0.231 & 0.231 & 0.230 & 0.230 & 0.230 & 0.512 & 0.513 & 0.514 & 0.512 & 0.512 & 1.943 & 0.511 \\
\hline LA & 20.185 & 20.178 & 20.192 & 20.197 & 20.074 & 20.094 & 68.408 & 68.384 & 68.431 & 68.447 & 68.024 & 69.021 & 68.092 \\
\hline LL & 27.782 & 27.775 & 27.773 & 27.770 & 27.738 & 27.709 & 94.226 & 94.206 & 94.201 & 94.186 & 94.081 & 93.950 & 93.980 \\
\hline LP & 77.589 & 77.556 & 77.649 & 77.902 & 77.032 & 77.181 & 262.524 & 262.411 & 262.723 & 263.585 & 260.607 & 262.281 & 261.145 \\
\hline GC & 14.012 & 14.010 & 14.007 & 14.012 & 14.014 & 13.987 & 35.696 & 35.688 & 35.683 & 35.702 & 35.700 & 38.432 & 35.630 \\
\hline LN & 235.981 & 235.640 & 235.695 & 235.903 & 235.874 & 235.748 & 795.593 & 794.486 & 794.681 & 795.327 & 795.249 & 799.975 & 794.826 \\
\hline SI & 0.399 & 0.399 & 0.400 & 0.399 & 0.399 & 0.398 & 0.939 & 0.939 & 0.941 & 0.939 & 0.939 & 0.986 & 0.938 \\
\hline LX & 28.891 & 28.884 & 28.920 & 28.967 & 28.876 & 28.879 & 97.940 & 97.915 & 98.044 & 98.202 & 97.891 & 98.190 & 97.903 \\
\hline CL & 1.121 & 1.121 & 1.122 & 1.123 & 1.112 & 1.113 & 3.976 & 3.977 & 3.978 & 3.982 & 3.946 & 3.990 & 3.948 \\
\hline $\mathrm{CO}$ & 1.120 & 1.121 & 1.121 & 1.126 & 1.113 & 1.113 & 3.970 & 3.971 & 3.974 & 3.989 & 3.945 & 3.989 & 3.943 \\
\hline HO & 2.988 & 2.985 & 2.984 & 2.995 & 2.970 & 2.967 & 10.582 & 10.573 & 10.569 & 10.610 & 10.522 & 10.832 & 10.509 \\
\hline PG & 2.876 & 2.878 & 2.881 & 2.892 & 2.859 & 2.864 & 10.209 & 10.216 & 10.225 & 10.265 & 10.148 & 22.135 & 10.166 \\
\hline NG & 0.062 & 0.062 & 0.062 & 0.062 & 0.061 & 0.061 & 0.222 & 0.222 & 0.222 & 0.222 & 0.221 & 0.373 & 0.221 \\
\hline XB & 2.924 & 2.923 & 2.923 & 2.937 & 2.909 & 2.907 & 9.958 & 9.951 & 9.950 & 10.004 & 9.904 & 19.216 & 9.899 \\
\hline
\end{tabular}

Note: red bold values indicate that they are smallest in different forecasting methods. 
Table 6: Relative forecasting performance evaluated using functional and multivariate error measures $R E r r_{f}$ and $R E r r_{m}$ for commodity futures forward curves at a daily resolution.

\begin{tabular}{|c|c|c|c|c|c|c|c|c|c|c|c|c|c|}
\hline \multicolumn{14}{|c|}{ Validation Period } \\
\hline \multirow[b]{2}{*}{ Symbol } & \multicolumn{6}{|c|}{ Functional Error } & \multicolumn{7}{|c|}{ Multivariate Error } \\
\hline & $\operatorname{FAR}(1)$ & FAR(2) & FAR(4) & FSAR & $\mathbf{P F}$ & Naïve & FAR(1) & FAR(2) & $\operatorname{FAR}(4)$ & FSAR & PF & DL & Naïve \\
\hline FC & $0.796 \%$ & $0.796 \%$ & $0.796 \%$ & $0.798 \%$ & $0.791 \%$ & $0.795 \%$ & $2.130 \%$ & $2.129 \%$ & $2.129 \%$ & $2.133 \%$ & $2.116 \%$ & $2.394 \%$ & $2.126 \%$ \\
\hline LC & $0.780 \%$ & $0.780 \%$ & $0.781 \%$ & $0.781 \%$ & $0.780 \%$ & $0.780 \%$ & $1.950 \%$ & $1.949 \%$ & $1.952 \%$ & $1.953 \%$ & $1.948 \%$ & $3.514 \%$ & $1.948 \%$ \\
\hline LH & $1.164 \%$ & $1.163 \%$ & $1.163 \%$ & $1.163 \%$ & $1.160 \%$ & $1.163 \%$ & $3.191 \%$ & $3.190 \%$ & $3.190 \%$ & $3.190 \%$ & $3.188 \%$ & $7.503 \%$ & $3.191 \%$ \\
\hline C & $2.030 \%$ & $2.029 \%$ & $2.030 \%$ & $2.033 \%$ & $2.026 \%$ & $2.025 \%$ & $4.586 \%$ & $4.584 \%$ & $4.588 \%$ & $4.594 \%$ & $4.576 \%$ & $5.093 \%$ & $4.575 \%$ \\
\hline $\mathbf{S}$ & $1.659 \%$ & $1.658 \%$ & $1.661 \%$ & $1.662 \%$ & $1.659 \%$ & $1.658 \%$ & $4.400 \%$ & $4.397 \%$ & $4.405 \%$ & $4.408 \%$ & $4.399 \%$ & $4.899 \%$ & $4.398 \%$ \\
\hline W & $2.203 \%$ & $2.202 \%$ & $2.203 \%$ & $2.209 \%$ & $2.201 \%$ & $2.200 \%$ & $5.000 \%$ & $4.997 \%$ & $5.000 \%$ & $5.013 \%$ & $4.994 \%$ & $5.787 \%$ & $4.992 \%$ \\
\hline $\mathrm{CC}$ & $1.839 \%$ & $1.840 \%$ & $1.841 \%$ & $1.841 \%$ & $1.839 \%$ & $1.838 \%$ & $4.138 \%$ & $4.139 \%$ & $4.141 \%$ & $4.142 \%$ & $4.137 \%$ & $4.145 \%$ & $4.135 \%$ \\
\hline KC & $1.756 \%$ & $1.761 \%$ & $1.762 \%$ & $1.757 \%$ & $1.757 \%$ & $1.757 \%$ & $3.953 \%$ & $3.963 \%$ & $3.966 \%$ & $3.954 \%$ & $3.954 \%$ & $3.986 \%$ & $3.953 \%$ \\
\hline KW & $2.050 \%$ & $2.049 \%$ & $2.050 \%$ & $2.050 \%$ & $2.046 \%$ & $2.044 \%$ & $4.622 \%$ & $4.619 \%$ & $4.621 \%$ & $4.621 \%$ & $4.614 \%$ & $5.375 \%$ & $4.608 \%$ \\
\hline CT & $1.809 \%$ & $1.812 \%$ & $1.813 \%$ & $1.811 \%$ & $1.808 \%$ & $1.807 \%$ & $4.082 \%$ & $4.088 \%$ & $4.089 \%$ & $4.086 \%$ & $4.079 \%$ & $4.639 \%$ & $4.078 \%$ \\
\hline SB & $2.228 \%$ & $2.235 \%$ & $2.241 \%$ & $2.234 \%$ & $2.220 \%$ & $2.226 \%$ & $4.561 \%$ & $4.575 \%$ & $4.587 \%$ & $4.574 \%$ & $4.543 \%$ & $20.847 \%$ & $4.556 \%$ \\
\hline $\mathbf{L A}^{-}$ & $1.666 \%$ & $1.667 \%$ & $1.667 \%$ & $1 . \overline{6} 6 \overline{6} \%$ & $1.664 \%$ & $1.664 \%$ & $5.549 \%$ & $5.551 \%$ & $5.552 \%$ & $5.548 \%$ & $\overline{5} . \overline{540 \%}$ & $5.871 \%$ & $5.540 \%$ \\
\hline LL & $2.786 \%$ & $2.785 \%$ & $2.784 \%$ & $2.786 \%$ & $2.778 \%$ & $2.778 \%$ & $9.250 \%$ & $9.245 \%$ & $9.242 \%$ & $9.251 \%$ & $9.223 \%$ & $9.360 \%$ & $9.222 \%$ \\
\hline $\mathbf{L P}$ & $2.294 \%$ & $2.297 \%$ & $2.302 \%$ & $2.308 \%$ & $2.284 \%$ & $2.286 \%$ & $7.612 \%$ & $7.623 \%$ & $7.640 \%$ & $7.659 \%$ & $7.581 \%$ & $8.458 \%$ & $7.587 \%$ \\
\hline GC & $1.398 \%$ & $1.398 \%$ & $1.398 \%$ & $1.397 \%$ & $1.397 \%$ & $1.397 \%$ & $3.422 \%$ & $3.420 \%$ & $3.422 \%$ & $3.418 \%$ & $3.418 \%$ & $3.552 \%$ & $3.420 \%$ \\
\hline LN & $2.846 \%$ & $2.845 \%$ & $2.844 \%$ & $2.848 \%$ & $2.847 \%$ & $2.845 \%$ & $9.415 \%$ & $9.412 \%$ & $9.406 \%$ & $9.421 \%$ & $9.418 \%$ & $9.490 \%$ & $9.410 \%$ \\
\hline SI & $2.590 \%$ & $2.589 \%$ & $2.589 \%$ & $2.592 \%$ & $2.587 \%$ & $2.585 \%$ & $5.788 \%$ & $5.786 \%$ & $5.788 \%$ & $5.792 \%$ & $5.781 \%$ & $6.198 \%$ & $5.778 \%$ \\
\hline LX & $2.579 \%$ & $2.578 \%$ & $2.584 \%$ & $2.580 \%$ & $2.580 \%$ & $2.578 \%$ & $8.538 \%$ & $8.536 \%$ & $8.556 \%$ & $8.543 \%$ & $8.542 \%$ & $8.660 \%$ & $8.535 \%$ \\
\hline$\overline{\mathbf{C}} \mathbf{L}^{-}$ & $2.141 \%$ & $2.143 \%$ & $2.149 \%$ & $2 . \overline{141 \%}$ & $2 . \overline{138 \%}$ & $2.136 \overline{\%}$ & $7.500 \%$ & $\overline{7} . \overline{507 \%}$ & $7.533 \%$ & $\overline{7} .501 \%$ & $\overline{7} . \overline{492 \%}$ & $7.7 \overline{4} 1 \overline{\%}$ & $7.485 \%$ \\
\hline $\mathrm{CO}$ & $2.037 \%$ & $2.038 \%$ & $2.044 \%$ & $2.040 \%$ & $2.030 \%$ & $2.029 \%$ & $7.128 \%$ & $7.132 \%$ & $7.155 \%$ & $7.138 \%$ & $7.104 \%$ & $7.377 \%$ & $7.101 \%$ \\
\hline HO & $1.955 \%$ & $1.956 \%$ & $1.958 \%$ & $1.952 \%$ & $1.948 \%$ & $1.946 \%$ & $6.826 \%$ & $6.831 \%$ & $6.836 \%$ & $6.816 \%$ & $6.802 \%$ & $7.267 \%$ & $6.796 \%$ \\
\hline PG & $1.399 \%$ & $1.400 \%$ & $1.404 \%$ & $1.404 \%$ & $1.397 \%$ & $1.398 \%$ & $4.860 \%$ & $4.862 \%$ & $4.875 \%$ & $4.877 \%$ & $4.854 \%$ & $7.807 \%$ & $4.857 \%$ \\
\hline NG & $2.187 \%$ & $2.186 \%$ & $2.190 \%$ & $2.188 \%$ & $2.182 \%$ & $2.178 \%$ & $7.975 \%$ & $7.972 \%$ & $7.982 \%$ & $7.972 \%$ & $7.951 \%$ & $16.751 \%$ & $7.936 \%$ \\
\hline $\mathrm{XB}$ & $1.500 \%$ & $1.501 \%$ & $1.501 \%$ & $1.498 \%$ & $1.500 \%$ & $1.499 \%$ & $5.021 \%$ & $5.024 \%$ & $5.027 \%$ & $5.016 \%$ & $5.022 \%$ & $7.111 \%$ & $5.019 \%$ \\
\hline \multicolumn{14}{|c|}{ Test Period } \\
\hline & \multicolumn{6}{|c|}{ Functional Error } & \multicolumn{7}{|c|}{ Multivariate Error } \\
\hline Symbol & $\operatorname{FAR}(1)$ & FAR(2) & FAR(4) & FSAR & PF & Naïve & $\operatorname{FAR}(1)$ & FAR(2) & FAR(4) & FSAR & PF & DL & Naïve \\
\hline FC & $1.001 \%$ & $1.002 \%$ & $1.001 \%$ & $1.003 \%$ & $0.989 \%$ & $0.990 \%$ & $2.656 \%$ & $2.659 \%$ & $2.654 \%$ & $2.660 \%$ & $2.625 \%$ & $2.951 \%$ & $2.627 \%$ \\
\hline LC & $0.850 \%$ & $0.852 \%$ & $0.850 \%$ & $0.850 \%$ & $0.849 \%$ & $0.848 \%$ & $2.104 \%$ & $2.107 \%$ & $2.102 \%$ & $2.101 \%$ & $2.097 \%$ & $3.597 \%$ & $2.097 \%$ \\
\hline LH & $1.108 \%$ & $1.109 \%$ & $1.108 \%$ & $1.108 \%$ & $1.105 \%$ & $1.108 \%$ & $3.024 \%$ & $3.025 \%$ & $3.025 \%$ & $3.022 \%$ & $3.017 \%$ & $8.063 \%$ & $3.024 \%$ \\
\hline C & $1.421 \%$ & $1.422 \%$ & $1.422 \%$ & $1.425 \%$ & $1.420 \%$ & $1.418 \%$ & $3.201 \%$ & $3.201 \%$ & $3.203 \%$ & $3.209 \%$ & $3.198 \%$ & $4.077 \%$ & $3.194 \%$ \\
\hline $\mathrm{s}$ & $1.180 \%$ & $1.182 \%$ & $1.180 \%$ & $1.183 \%$ & $1.179 \%$ & $1.178 \%$ & $3.138 \%$ & $3.144 \%$ & $3.138 \%$ & $3.147 \%$ & $3.136 \%$ & $4.149 \%$ & $3.133 \%$ \\
\hline w & $1.512 \%$ & $1.512 \%$ & $1.511 \%$ & $1.516 \%$ & $1.513 \%$ & $1.511 \%$ & $3.435 \%$ & $3.435 \%$ & $3.434 \%$ & $3.444 \%$ & $3.437 \%$ & $3.531 \%$ & $3.433 \%$ \\
\hline $\mathrm{CC}$ & $1.457 \%$ & $1.457 \%$ & $1.461 \%$ & $1.457 \%$ & $1.456 \%$ & $1.455 \%$ & $3.291 \%$ & $3.291 \%$ & $3.301 \%$ & $3.292 \%$ & $3.290 \%$ & $3.291 \%$ & $3.287 \%$ \\
\hline KC & $1.934 \%$ & $1.938 \%$ & $1.940 \%$ & $1.933 \%$ & $1.931 \%$ & $1.931 \%$ & $4.353 \%$ & $4.363 \%$ & $4.368 \%$ & $4.353 \%$ & $4.348 \%$ & $4.351 \%$ & $4.346 \%$ \\
\hline KW & $1.469 \%$ & $1.468 \%$ & $1.469 \%$ & $1.473 \%$ & $1.467 \%$ & $1.466 \%$ & $3.322 \%$ & $3.320 \%$ & $3.322 \%$ & $3.331 \%$ & $3.318 \%$ & $3.470 \%$ & $3.316 \%$ \\
\hline $\mathrm{CT}$ & $1.181 \%$ & $1.182 \%$ & $1.189 \%$ & $1.181 \%$ & $1.176 \%$ & $1.178 \%$ & $2.712 \%$ & $2.717 \%$ & $2.732 \%$ & $2.715 \%$ & $2.703 \%$ & $3.004 \%$ & $2.708 \%$ \\
\hline SB & $1.403 \%$ & $1.403 \%$ & $1.406 \%$ & $1.403 \%$ & $1.404 \%$ & $1.400 \%$ & $2.907 \%$ & $2.908 \%$ & $2.914 \%$ & $2.907 \%$ & $2.907 \%$ & $11.470 \%$ & $2.900 \%$ \\
\hline LA & $1.085 \%$ & $1.084 \%$ & $1.085 \%$ & $1.085 \%$ & $1.079 \%$ & $1.080 \%$ & $3.609 \%$ & $3.608 \%$ & $3.610 \%$ & $3.612 \%$ & $3.589 \%$ & $3.644 \%$ & $3.593 \%$ \\
\hline LL & $1.381 \%$ & $1.381 \%$ & $1.381 \%$ & $1.381 \%$ & $1.379 \%$ & $1.378 \%$ & $4.585 \%$ & $4.584 \%$ & $4.583 \%$ & $4.583 \%$ & $4.578 \%$ & $4.574 \%$ & $4.572 \%$ \\
\hline LP & $1.226 \%$ & $1.225 \%$ & $1.226 \%$ & $1.229 \%$ & $1.217 \%$ & $1.219 \%$ & $4.065 \%$ & $4.064 \%$ & $4.068 \%$ & $4.077 \%$ & $4.035 \%$ & $4.058 \%$ & $4.041 \%$ \\
\hline GC & $1.058 \%$ & $1.058 \%$ & $1.057 \%$ & $1.058 \%$ & $1.058 \%$ & $1.055 \%$ & $2.586 \%$ & $2.586 \%$ & $2.586 \%$ & $2.587 \%$ & $2.587 \%$ & $2.771 \%$ & $2.581 \%$ \\
\hline LN & $1.748 \%$ & $1.746 \%$ & $1.747 \%$ & $1.748 \%$ & $1.747 \%$ & $1.746 \%$ & $5.787 \%$ & $5.782 \%$ & $5.785 \%$ & $5.787 \%$ & $5.786 \%$ & $5.856 \%$ & $5.782 \%$ \\
\hline SI & $1.794 \%$ & $1.793 \%$ & $1.796 \%$ & $1.792 \%$ & $1.793 \%$ & $1.790 \%$ & $4.006 \%$ & $4.004 \%$ & $4.010 \%$ & $4.001 \%$ & $4.004 \%$ & $4.243 \%$ & $3.998 \%$ \\
\hline LX & $1.367 \%$ & $1.367 \%$ & $1.368 \%$ & $1.370 \%$ & $1.366 \%$ & $1.366 \%$ & $4.541 \%$ & $4.540 \%$ & $4.545 \%$ & $4.550 \%$ & $4.537 \%$ & $4.542 \%$ & $4.537 \%$ \\
\hline$\overline{C L}^{-}$ & $1.821 \%$ & $1.821 \%$ & $1.821 \%$ & $1.823 \%$ & $1.804 \%$ & $1.805 \%$ & $6.367 \%$ & $\overline{6} . \overline{370 \%}$ & $6.368 \%$ & $6.375 \%$ & $\overline{6.309 \%}$ & $6.362 \%$ & $6.313 \%$ \\
\hline $\mathrm{CO}$ & $1.719 \%$ & $1.719 \%$ & $1.721 \%$ & $1.726 \%$ & $1.706 \%$ & $1.707 \%$ & $6.009 \%$ & $6.010 \%$ & $6.017 \%$ & $6.036 \%$ & $5.967 \%$ & $6.024 \%$ & $5.968 \%$ \\
\hline HO & $1.563 \%$ & $1.562 \%$ & $1.561 \%$ & $1.565 \%$ & $1.553 \%$ & $1.551 \%$ & $5.445 \%$ & $5.444 \%$ & $5.441 \%$ & $5.456 \%$ & $5.411 \%$ & $5.546 \%$ & $5.407 \%$ \\
\hline PG & $1.842 \%$ & $1.842 \%$ & $1.844 \%$ & $1.849 \%$ & $1.831 \%$ & $1.835 \%$ & $6.447 \%$ & $6.448 \%$ & $6.454 \%$ & $6.471 \%$ & $6.410 \%$ & $13.812 \%$ & $6.422 \%$ \\
\hline NG & $1.838 \%$ & $1.837 \%$ & $1.836 \%$ & $1.836 \%$ & $1.828 \%$ & $1.828 \%$ & $6.599 \%$ & $6.600 \%$ & $6.594 \%$ & $6.592 \%$ & $6.563 \%$ & $11.514 \%$ & $6.564 \%$ \\
\hline XB & $1.806 \%$ & $1.804 \%$ & $1.803 \%$ & $1.813 \%$ & $1.795 \%$ & $1.795 \%$ & $6.078 \%$ & $6.070 \%$ & $6.065 \%$ & $6.102 \%$ & $6.041 \%$ & $11.566 \%$ & $6.039 \%$ \\
\hline
\end{tabular}

Note: red bold values indicate that they are smallest in different forecasting methods. 
sequence of curves forming a weak white noise and exhibiting conditional heteroscedasticity. We applied several functional time series forecasting methods to the log-differenced forward curves, as well as the multivariate method of Diebold \& Li (2006), and found that in general the functional methods were superior to their multivariate counterparts, and in some cases even beat the naïve forecast in test period comparisons. Among the functional forecasting methods, the FAR(1) model estimated using predictive factors Kargin \& Onatski (2008) performed slightly better than the alternatives and benchmarks considered. 


\section{Appendix A Additional technical information}

\section{A.1 Implementation of functional KPSS and portmanteau tests}

As discussed in Section 3 , the functional KPSS statistic defined as

$$
\operatorname{fKPSS}_{N}=\iint Z_{N}^{2}(x, t) d t d x
$$

satisfies under mild weak dependence and moment conditions on the log-differenced series $X_{i}(t)$ that

$$
\mathrm{fKPSS}_{N} \stackrel{D}{\longrightarrow} \Xi_{K P S S}, N \rightarrow \infty
$$

where $\Xi_{K P S S}$ is a random variable that can be expressed in terms of the eigenvalues of the long-run covariance operator

$$
C_{L R}(x)(t)=\int c_{L R}(t, s) x(s) d s,
$$

with

$$
c_{L R}(t, s)=\sum_{\ell=-\infty}^{\infty} \operatorname{cov}\left(X_{0}(t), X_{\ell}(s)\right),
$$

see Horváth et al. (2014) for details. In order to estimate these eigenvalues and subsequently the limiting distribution, we used a kernel lag-window estimator of $c_{L R}$ defined by

$$
\hat{c}_{L R}(t, s)=\sum_{\ell=-\infty}^{\infty} K(\ell / h) \hat{c}_{\ell}(t, s)
$$

with a flat-top kernel

$$
K(x)= \begin{cases}1, & \text { if } 0 \leq t<1 \\ 1.1-|t|, & \text { if } 0.1 \leq t<1.1 \\ 0, & \text { if }|t| \geq 1.1\end{cases}
$$

and bandwidth $h=N^{1 / 2}$.

Regarding the portmanteau tests, under the conditions of Theorem 2 in Kokoszka et al. (2017), we have under $\mathcal{H}_{0, i i d}$ and $\mathcal{H}_{0, c h}$, respectively, that

$$
V_{N, K} \stackrel{D}{\longrightarrow} \Theta_{K, i i d}, \quad N \rightarrow \infty,
$$


and

$$
V_{N, K} \stackrel{D}{\longrightarrow} \Theta_{K, c h}, \quad N \rightarrow \infty
$$

Both $\Theta_{K, i i d}$ and $\Theta_{K, c h}$ can be approximated using a Welch style approximation of the form

$$
\Theta_{K, i i d} \stackrel{D}{\approx} \beta_{i i d} \chi_{\nu_{i i d}}^{2}
$$

and

$$
\Theta_{K, c h} \stackrel{D}{\approx} \beta_{c h} \chi_{\nu_{c h}}^{2}
$$

where the constants $\beta$ and $\nu$ are estimated in order that the scaled chi-square approximations share approximately the same first two moments with the limiting distribution. Estimating $\beta_{c h}$ and $\nu_{c h}$ is discussed in detail in Section 2 of Kokoszka et al. (2017), and amounts to taking

$$
\hat{\beta}_{c h}=\frac{\hat{\sigma}_{K, c h}^{2}}{2 \hat{\mu}_{K, c h}} \quad \text { and } \quad \hat{\nu}_{c h}=\frac{2 \hat{\mu}_{K, c h}^{2}}{\hat{\sigma}_{K, c h}^{2}},
$$

where $\hat{\mu}_{K, c h}$ and $\hat{\sigma}_{K, c h}^{2}$ are estimators of the mean and variance of $\Theta_{K, c h}$. It follows by examining equation (15) in Kokoszka et al. (2017) that under $\mathcal{H}_{0, \text { iid }}$ as opposed to $\mathcal{H}_{0, \text { ch }}$,

$$
E \Theta_{K, i i d}=K\left(\int \operatorname{cov}\left(X_{0}(t), X_{0}(t)\right) d t\right)^{2}, \operatorname{Var}\left(\Theta_{K, i i d}\right)=2 K\left(\iint \operatorname{cov}\left(X_{0}(t), X_{0}(s)\right) d t d s\right)^{2}
$$

which can be similarly estimated, yielding estimates of $\beta_{i i d}$ and $\nu_{i i d}$.

\section{A.2 Estimation of FSAR models}

We estimate these models using functional principal component analysis and the least squares principle: Let $\hat{v}_{1}, \ldots, \hat{v}_{p}$ be the first $p$ functional principal components. Let $\ell_{1}, \ldots ., \ell_{k}$ denote the pre-specified lags. We assume that the kernels $\psi_{\ell, i}$ can be approximated by

$$
\psi_{\ell, i}(t, s) \approx \sum_{j, r=1}^{p} \boldsymbol{\Phi}_{\ell, i}[j, r] \hat{v}_{j}(t) \hat{v}_{r}(s), \quad \boldsymbol{\Phi}_{i} \in \mathbb{R}^{p \times p},
$$

and further that

$$
X_{n}(t) \approx \sum_{j=1}^{p}\left\langle X_{n}, \hat{v}_{j}\right\rangle \hat{v}_{j}(t), \quad \mathbf{X}_{n}=\left(\left\langle X_{n}, \hat{v}_{1},\right\rangle, \ldots,\left\langle X_{n}, \hat{v}_{d}\right\rangle\right)^{\top} \in \mathbb{R}^{p}
$$

Let

$$
\boldsymbol{\Phi}=\left(\begin{array}{c}
\boldsymbol{\Phi}_{\ell, 1} \\
\vdots \\
\boldsymbol{\Phi}_{\ell, k}
\end{array}\right) \in \mathbb{R}^{k p \times p}
$$


Rewriting the FSAR equations using these approximations, we have that with

$$
\begin{gathered}
\mathbf{X}_{L, p}=\left(\mathbf{X}_{i-\ell_{1}}^{\top}, \ldots, \mathbf{X}_{i-\ell_{k}}^{\top}, i=\ell_{k}+1, \ldots, N\right)^{\top} \in \mathbb{R}^{N-\ell_{k} \times k p}, \\
\mathbf{X}_{R, p}=\left(\begin{array}{c}
\mathbf{X}_{\ell_{k}+1}^{\top} \\
\vdots \\
\mathbf{X}_{N}^{\top}
\end{array}\right) \in \mathbb{R}^{N-\ell_{k} \times p}
\end{gathered}
$$

the least squares estimator for $\boldsymbol{\Phi}$ is

$$
\widehat{\boldsymbol{\Phi}}=\left(\mathbf{X}_{L, p}^{\top} \mathbf{X}_{L, p}\right)^{-1} \mathbf{X}_{L, p} \mathbf{X}_{R, p}=:\left(\begin{array}{c}
\hat{\mathbf{\Phi}}_{\ell, 1} \\
\vdots \\
\hat{\mathbf{\Phi}}_{\ell, k}
\end{array}\right) \in \mathbb{R}^{k p \times p}
$$

This yields estimates of the kernel functions $\psi_{\ell, i}(t, s)$ given by

$$
\hat{\psi}_{\ell, i}(t, s) \approx \sum_{j, r=1}^{p} \hat{\boldsymbol{\Phi}}_{\ell, i}[j, r] \hat{v}_{j}(t) \hat{v}_{r}(s), \quad \boldsymbol{\Phi}_{i} \in \mathbb{R}^{p \times p} .
$$




\section{Appendix B Results for forecasting at different temporal resolutions}

Table 7: Forecasting performance evaluated using functional and multivariate error measures for commodity futures forward curves at a weekly resolution.

\begin{tabular}{|c|c|c|c|c|c|c|c|c|c|c|c|c|c|}
\hline \multicolumn{14}{|c|}{ Validation Period } \\
\hline \multirow{2}{*}{ Symbol } & \multicolumn{6}{|c|}{ Functional Error } & \multicolumn{7}{|c|}{ Multivariate Error } \\
\hline & FAR(1) & $\operatorname{FAR}(2)$ & FAR(4) & FSAR & PF & Naïve & $\operatorname{FAR}(1)$ & FAR(2) & FAR(4) & FSAR & PF & DL & Naïve \\
\hline FC & 0.799 & 0.798 & 0.798 & 0.799 & 0.793 & 0.798 & 2.334 & 2.332 & 2.332 & 2.333 & 2.318 & 2.612 & 2.331 \\
\hline LC & 0.737 & 0.738 & 0.739 & 0.739 & 0.738 & 0.738 & 1.898 & 1.899 & 1.902 & 1.901 & 1.898 & 3.339 & 1.899 \\
\hline LH & 0.848 & 0.848 & 0.848 & 0.848 & 0.847 & 0.848 & 2.383 & 2.383 & 2.383 & 2.382 & 2.379 & 5.362 & 2.383 \\
\hline $\mathrm{C}$ & 9.262 & 9.259 & 9.265 & 9.270 & 9.246 & 9.249 & 22.007 & 22.006 & 22.018 & 22.027 & 21.966 & 25.480 & 21.975 \\
\hline $\mathrm{s}$ & 17.300 & 17.290 & 17.315 & 17.332 & 17.296 & 17.293 & 47.715 & 47.687 & 47.761 & 47.807 & 47.702 & 53.755 & 47.692 \\
\hline w & 15.228 & 15.206 & 15.215 & 15.227 & 15.199 & 15.198 & 36.040 & 35.991 & 36.016 & 36.043 & 35.966 & 42.133 & 35.971 \\
\hline $\mathrm{CC}$ & 45.136 & 45.150 & 45.183 & 45.237 & 45.140 & 45.124 & 106.656 & 106.697 & 106.780 & 106.902 & 106.665 & 106.966 & 106.625 \\
\hline $\mathrm{KC}$ & 2.770 & 2.779 & 2.778 & 2.773 & 2.774 & 2.774 & 6.521 & 6.543 & 6.541 & 6.531 & 6.532 & 6.605 & 6.532 \\
\hline KW & 14.744 & 14.737 & 14.737 & 14.720 & 14.657 & 14.678 & 34.833 & 34.821 & 34.826 & 34.766 & 34.636 & 40.150 & 34.690 \\
\hline CT & 1.620 & 1.620 & 1.616 & 1.620 & 1.617 & 1.618 & 3.869 & 3.868 & 3.856 & 3.870 & 3.862 & 4.616 & 3.865 \\
\hline SB & 0.388 & 0.389 & 0.390 & 0.389 & 0.386 & 0.388 & 0.879 & 0.881 & 0.884 & 0.880 & 0.874 & 4.680 & 0.878 \\
\hline $\mathrm{LA}^{-}$ & 38.395 & $38 . \overline{401}$ & 38.413 & 38.422 & $\overline{38} . \overline{334}$ & 38.356 & 129.781 & 129.810 & $\overline{129}-\overline{853}$ & 129.873 & $\overline{129.573}$ & $\overline{139.121}$ & 129.649 \\
\hline LL & 57.115 & 57.097 & 57.066 & 57.151 & 56.952 & 56.953 & 193.067 & 193.008 & 192.896 & 193.194 & 192.510 & 196.365 & 192.528 \\
\hline LP & 144.956 & 145.194 & 145.447 & 145.974 & 144.442 & 144.504 & 490.402 & 491.227 & 492.069 & 493.917 & 488.726 & 567.637 & 488.933 \\
\hline GC & 13.288 & 13.292 & 13.298 & 13.287 & 13.276 & 13.290 & 33.812 & 33.824 & 33.839 & 33.811 & 33.781 & 34.854 & 33.818 \\
\hline LN & 641.845 & 641.863 & 642.030 & 642.143 & 642.524 & 642.004 & 2165.755 & 2165.722 & 2166.075 & 2166.677 & 2168.029 & 2196.155 & 2166.579 \\
\hline SI & 0.517 & 0.518 & 0.518 & 0.517 & 0.517 & 0.517 & 1.202 & 1.202 & 1.202 & 1.202 & 1.201 & 1.253 & 1.200 \\
\hline LX & 61.349 & 61.348 & 61.478 & 61.432 & 61.411 & 61.367 & 206.402 & 206.390 & 206.821 & 206.686 & 206.608 & 211.740 & 206.489 \\
\hline$\overline{\mathbf{C}} \mathbf{L}^{-}$ & 1.687 & $1 . \overline{6} \overline{7}$ & 1.690 & 1.688 & 1.685 & 1.684 & 5.952 & 5.953 & $-\overline{5} . \overline{963}$ & 5.955 & $5 . \overline{9} 4 \overline{7}$ & $-\overline{6.183}$ & 5.943 \\
\hline $\mathrm{CO}$ & 1.651 & 1.651 & 1.654 & 1.655 & 1.648 & 1.648 & 5.824 & 5.824 & 5.835 & 5.840 & 5.814 & 6.083 & 5.814 \\
\hline но & 4.421 & 4.425 & 4.424 & 4.418 & 4.415 & 4.413 & 15.621 & 15.636 & 15.632 & 15.610 & 15.605 & 16.627 & 15.595 \\
\hline PG & 3.674 & 3.675 & 3.685 & 3.685 & 3.674 & 3.676 & 13.221 & 13.226 & 13.259 & 13.265 & 13.225 & 21.254 & 13.231 \\
\hline NG & 0.163 & 0.163 & 0.163 & 0.163 & 0.162 & 0.162 & 0.580 & 0.580 & 0.580 & 0.580 & 0.578 & 1.281 & 0.577 \\
\hline XB & 3.765 & 3.768 & 3.770 & 3.766 & 3.769 & 3.768 & 12.853 & 12.862 & 12.870 & 12.858 & 12.869 & 18.342 & 12.864 \\
\hline \multicolumn{14}{|c|}{ Test Period } \\
\hline & \multicolumn{6}{|c|}{ Functional Error } & \multicolumn{7}{|c|}{ Multivariate Error } \\
\hline Symbol & $\operatorname{FAR}(1)$ & $\operatorname{FAR}(2)$ & FAR(4) & FSAR & PF & Naïve & $\operatorname{FAR}(1)$ & FAR $(2)$ & FAR(4) & FSAR & PF & DL & Naïve \\
\hline FC & 1.472 & 1.474 & 1.472 & 1.475 & 1.452 & 1.458 & 4.272 & 4.275 & 4.271 & 4.281 & 4.218 & 4.753 & 4.232 \\
\hline LC & 1.047 & 1.047 & 1.047 & 1.047 & 1.045 & 1.045 & 2.694 & 2.691 & 2.691 & 2.690 & 2.686 & 4.609 & 2.686 \\
\hline LH & 0.880 & 0.881 & 0.881 & 0.880 & 0.880 & 0.880 & 2.490 & 2.491 & 2.491 & 2.489 & 2.488 & 6.536 & 2.491 \\
\hline C & 6.917 & 6.917 & 6.922 & 6.938 & 6.909 & 6.902 & 16.394 & 16.392 & 16.403 & 16.442 & 16.375 & 22.825 & 16.363 \\
\hline $\mathrm{s}$ & 13.501 & 13.528 & 13.500 & 13.540 & 13.500 & 13.489 & 37.575 & 37.668 & 37.566 & 37.679 & 37.567 & 51.402 & 37.538 \\
\hline $\mathbf{w}$ & 8.973 & 8.973 & 8.968 & 8.993 & 8.981 & 8.971 & 21.176 & 21.175 & 21.163 & 21.225 & 21.194 & 22.098 & 21.171 \\
\hline $\mathrm{CC}$ & 34.637 & 34.639 & 34.741 & 34.640 & 34.637 & 34.612 & 82.231 & 82.233 & 82.484 & 82.246 & 82.233 & 82.303 & 82.173 \\
\hline $\mathrm{KC}$ & 3.054 & 3.065 & 3.069 & 3.054 & 3.050 & 3.049 & 7.164 & 7.190 & 7.199 & 7.165 & 7.155 & 7.165 & 7.152 \\
\hline KW & 9.102 & 9.095 & 9.106 & 9.127 & 9.091 & 9.088 & 21.422 & 21.403 & 21.430 & 21.487 & 21.395 & 22.620 & 21.386 \\
\hline CT & 0.849 & 0.849 & 0.857 & 0.849 & 0.845 & 0.847 & 2.060 & 2.062 & 2.079 & 2.060 & 2.051 & 2.326 & 2.055 \\
\hline SB & 0.231 & 0.232 & $\begin{array}{r}0.232 \\
-\end{array}$ & 0.231 & 0.231 & $\begin{array}{r}0.231 \\
-\end{array}$ & 0.513 & 0.513 & 0.514 & 0.513 & 0.512 & 1.943 & 0.511 \\
\hline LA & 20.331 & 20.323 & 20.336 & 20.342 & 20.217 & 20.242 & 68.541 & 68.511 & 68.557 & 68.577 & 68.152 & 69.021 & 68.232 \\
\hline LL & 27.927 & 27.933 & 27.936 & 27.915 & 27.887 & 27.854 & 94.232 & 94.250 & 94.260 & 94.194 & 94.103 & 93.950 & 93.989 \\
\hline LP & 78.075 & 78.058 & 78.076 & 78.329 & 77.456 & 77.609 & 262.753 & 262.693 & 262.755 & 263.615 & 260.648 & 262.281 & 261.197 \\
\hline GC & 14.075 & 14.073 & 14.071 & 14.082 & 14.077 & 14.050 & 35.696 & 35.689 & 35.683 & 35.721 & 35.701 & 38.432 & 35.630 \\
\hline LN & 237.134 & 236.785 & 236.839 & 237.048 & 237.029 & 236.901 & 795.470 & 794.348 & 794.536 & 795.176 & 795.131 & 799.975 & 794.709 \\
\hline SI & 0.401 & 0.401 & 0.401 & 0.400 & 0.401 & 0.400 & 0.939 & 0.939 & 0.941 & 0.939 & 0.939 & 0.986 & 0.938 \\
\hline LX & 29.041 & 29.034 & 29.071 & 29.117 & 29.026 & 29.029 & 97.937 & 97.913 & 98.041 & 98.197 & 97.888 & 98.190 & 97.900 \\
\hline $\mathrm{CL}^{-}$ & 1.126 & 1.126 & 1.127 & 1.128 & 1.117 & 1.118 & 3.982 & 3.983 & 3.984 & 3.989 & 3.952 & 3.990 & 3.954 \\
\hline $\mathrm{CO}$ & 1.125 & 1.126 & 1.126 & 1.131 & 1.118 & 1.118 & 3.974 & 3.976 & 3.978 & 3.994 & 3.949 & 3.989 & 3.948 \\
\hline Hо & 2.997 & 2.995 & 2.994 & 3.002 & 2.980 & 2.977 & 10.589 & 10.583 & 10.578 & 10.609 & 10.531 & 10.832 & 10.518 \\
\hline PG & 2.919 & 2.922 & 2.925 & 2.936 & 2.903 & 2.908 & 10.304 & 10.317 & 10.325 & 10.365 & 10.247 & 22.135 & 10.265 \\
\hline NG & 0.062 & 0.062 & 0.062 & 0.062 & 0.062 & 0.062 & 0.223 & 0.223 & 0.223 & 0.223 & 0.222 & 0.373 & 0.222 \\
\hline XB & 2.968 & 2.965 & 2.965 & 2.976 & 2.951 & 2.949 & 10.050 & 10.040 & 10.040 & 10.077 & 9.992 & 19.216 & 9.987 \\
\hline
\end{tabular}

Note: red bold values indicate that they are smallest in different forecasting methods. 
Table 8: Relative forecasting performance evaluated using functional and multivariate error measures for commodity futures forward curves at a weekly resolution.

\begin{tabular}{|c|c|c|c|c|c|c|c|c|c|c|c|c|c|}
\hline \multicolumn{14}{|c|}{ Validation Period } \\
\hline \multirow[b]{2}{*}{ Symbol } & \multicolumn{6}{|c|}{ Functional Error } & \multicolumn{7}{|c|}{ Multivariate Error } \\
\hline & $\operatorname{FAR}(1)$ & FAR(2) & FAR(4) & FSAR & $\mathbf{P F}$ & Naïve & FAR(1) & FAR(2) & $\operatorname{FAR}(4)$ & FSAR & PF & DL & Naïve \\
\hline FC & $0.799 \%$ & $0.798 \%$ & $0.799 \%$ & $0.800 \%$ & $0.794 \%$ & $0.798 \%$ & $2.137 \%$ & $2.135 \%$ & $2.136 \%$ & $2.138 \%$ & $2.125 \%$ & $2.394 \%$ & $2.134 \%$ \\
\hline LC & $0.786 \%$ & $0.786 \%$ & $0.788 \%$ & $0.787 \%$ & $0.786 \%$ & $0.786 \%$ & $1.961 \%$ & $1.962 \%$ & $1.965 \%$ & $1.964 \%$ & $1.961 \%$ & $3.514 \%$ & $1.961 \%$ \\
\hline LH & $1.201 \%$ & $1.201 \%$ & $1.201 \%$ & $1.201 \%$ & $1.198 \%$ & $1.201 \%$ & $3.302 \%$ & $3.301 \%$ & $3.301 \%$ & $3.302 \%$ & $3.297 \%$ & $7.503 \%$ & $3.301 \%$ \\
\hline C & $2.031 \%$ & $2.030 \%$ & $2.031 \%$ & $2.033 \%$ & $2.027 \%$ & $2.027 \%$ & $4.590 \%$ & $4.589 \%$ & $4.592 \%$ & $4.596 \%$ & $4.581 \%$ & $5.093 \%$ & $4.580 \%$ \\
\hline $\mathbf{S}$ & $1.660 \%$ & $1.659 \%$ & $1.662 \%$ & $1.663 \%$ & $1.660 \%$ & $1.660 \%$ & $4.407 \%$ & $4.405 \%$ & $4.413 \%$ & $4.413 \%$ & $4.407 \%$ & $4.899 \%$ & $4.406 \%$ \\
\hline W & $2.205 \%$ & $2.204 \%$ & $2.205 \%$ & $2.210 \%$ & $2.203 \%$ & $2.202 \%$ & $5.007 \%$ & $5.004 \%$ & $5.008 \%$ & $5.019 \%$ & $5.001 \%$ & $5.787 \%$ & $4.999 \%$ \\
\hline $\mathrm{CC}$ & $1.839 \%$ & $1.840 \%$ & $1.841 \%$ & $1.841 \%$ & $1.839 \%$ & $1.838 \%$ & $4.139 \%$ & $4.142 \%$ & $4.144 \%$ & $4.144 \%$ & $4.140 \%$ & $4.145 \%$ & $4.137 \%$ \\
\hline KC & $1.759 \%$ & $1.765 \%$ & $1.765 \%$ & $1.759 \%$ & $1.760 \%$ & $1.759 \%$ & $3.961 \%$ & $3.974 \%$ & $3.975 \%$ & $3.962 \%$ & $3.962 \%$ & $3.986 \%$ & $3.961 \%$ \\
\hline KW & $2.051 \%$ & $2.050 \%$ & $2.051 \%$ & $2.051 \%$ & $2.048 \%$ & $2.045 \%$ & $4.625 \%$ & $4.622 \%$ & $4.625 \%$ & $4.624 \%$ & $4.617 \%$ & $5.375 \%$ & $4.611 \%$ \\
\hline CT & $1.812 \%$ & $1.814 \%$ & $1.815 \%$ & $1.813 \%$ & $1.810 \%$ & $1.809 \%$ & $4.101 \%$ & $4.106 \%$ & $4.106 \%$ & $4.104 \%$ & $4.097 \%$ & $4.639 \%$ & $4.096 \%$ \\
\hline SB & $2.230 \%$ & $2.236 \%$ & $2.242 \%$ & $2.236 \%$ & $2.222 \%$ & $2.227 \%$ & $4.570 \%$ & $4.583 \%$ & $4.594 \%$ & $4.584 \%$ & $4.554 \%$ & $20.847 \%$ & $4.564 \%$ \\
\hline $\mathbf{L A}^{-}$ & $1.666 \%$ & $1.667 \%$ & $1.667 \%$ & $1 . \overline{6} 6 \overline{6} \%$ & $1.664 \%$ & $1.664 \%$ & $5.551 \%$ & $\overline{5} . \overline{5} 5 \%$ & $5.554 \%$ & $5.550 \%$ & $\overline{5} . \overline{543 \%}$ & $5.871 \%$ & $5.542 \%$ \\
\hline LL & $2.786 \%$ & $2.784 \%$ & $2.784 \%$ & $2.786 \%$ & $2.778 \%$ & $2.777 \%$ & $9.250 \%$ & $9.246 \%$ & $9.245 \%$ & $9.253 \%$ & $9.223 \%$ & $9.360 \%$ & $9.223 \%$ \\
\hline $\mathbf{L P}$ & $2.294 \%$ & $2.298 \%$ & $2.302 \%$ & $2.307 \%$ & $2.284 \%$ & $2.285 \%$ & $7.616 \%$ & $7.628 \%$ & $7.641 \%$ & $7.658 \%$ & $7.580 \%$ & $8.458 \%$ & $7.586 \%$ \\
\hline GC & $1.398 \%$ & $1.398 \%$ & $1.399 \%$ & $1.396 \%$ & $1.397 \%$ & $1.398 \%$ & $3.422 \%$ & $3.421 \%$ & $3.423 \%$ & $3.417 \%$ & $3.419 \%$ & $3.552 \%$ & $3.420 \%$ \\
\hline LN & $2.848 \%$ & $2.847 \%$ & $2.845 \%$ & $2.850 \%$ & $2.849 \%$ & $2.846 \%$ & $9.421 \%$ & $9.417 \%$ & $9.411 \%$ & $9.428 \%$ & $9.424 \%$ & $9.490 \%$ & $9.416 \%$ \\
\hline SI & $2.589 \%$ & $2.589 \%$ & $2.589 \%$ & $2.592 \%$ & $2.587 \%$ & $2.585 \%$ & $5.786 \%$ & $5.787 \%$ & $5.788 \%$ & $5.794 \%$ & $5.782 \%$ & $6.198 \%$ & $5.779 \%$ \\
\hline LX & $2.578 \%$ & $2.578 \%$ & $2.584 \%$ & $2.580 \%$ & $2.580 \%$ & $2.578 \%$ & $8.539 \%$ & $8.537 \%$ & $8.557 \%$ & $8.545 \%$ & $8.544 \%$ & $8.660 \%$ & $8.537 \%$ \\
\hline$\overline{\mathbf{C}} \mathbf{L}^{-}$ & $2.140 \%$ & $2.142 \%$ & $2.149 \%$ & $2 . \overline{141 \%}$ & $2 . \overline{138 \%}$ & $2.136 \overline{\%}$ & $7.507 \%$ & $\overline{7} . \overline{514} \%$ & $7.540 \%$ & $\overline{7.508 \%}$ & $\overline{7} . \overline{499 \%}$ & $7.7 \overline{4} 1 \overline{\%}$ & $7.493 \%$ \\
\hline $\mathrm{CO}$ & $2.037 \%$ & $2.038 \%$ & $2.045 \%$ & $2.041 \%$ & $2.031 \%$ & $2.030 \%$ & $7.135 \%$ & $7.139 \%$ & $7.165 \%$ & $7.148 \%$ & $7.115 \%$ & $7.377 \%$ & $7.112 \%$ \\
\hline HO & $1.955 \%$ & $1.957 \%$ & $1.959 \%$ & $1.952 \%$ & $1.948 \%$ & $1.947 \%$ & $6.829 \%$ & $6.838 \%$ & $6.843 \%$ & $6.820 \%$ & $6.808 \%$ & $7.267 \%$ & $6.802 \%$ \\
\hline PG & $1.410 \%$ & $1.410 \%$ & $1.414 \%$ & $1.414 \%$ & $1.408 \%$ & $1.408 \%$ & $4.888 \%$ & $4.889 \%$ & $4.903 \%$ & $4.904 \%$ & $4.881 \%$ & $7.807 \%$ & $4.884 \%$ \\
\hline NG & $2.206 \%$ & $2.205 \%$ & $2.207 \%$ & $2.205 \%$ & $2.200 \%$ & $2.195 \%$ & $8.060 \%$ & $8.064 \%$ & $8.065 \%$ & $8.055 \%$ & $8.035 \%$ & $16.751 \%$ & $8.019 \%$ \\
\hline $\mathrm{XB}$ & $1.509 \%$ & $1.510 \%$ & $1.510 \%$ & $1.508 \%$ & $1.509 \%$ & $1.508 \%$ & $5.048 \%$ & $5.048 \%$ & $5.051 \%$ & $5.042 \%$ & $5.047 \%$ & $7.111 \%$ & $5.044 \%$ \\
\hline \multicolumn{14}{|c|}{ Test Period } \\
\hline & \multicolumn{6}{|c|}{ Functional Error } & \multicolumn{7}{|c|}{ Multivariate Error } \\
\hline Symbol & $\operatorname{FAR}(1)$ & FAR(2) & FAR(4) & FSAR & PF & Naïve & FAR(1) & FAR(2) & FAR $(4)$ & FSAR & PF & DL & Naïve \\
\hline FC & $1.007 \%$ & $1.007 \%$ & $1.006 \%$ & $1.008 \%$ & $0.994 \%$ & $0.996 \%$ & $2.669 \%$ & $2.671 \%$ & $2.667 \%$ & $2.674 \%$ & $2.636 \%$ & $2.951 \%$ & $2.640 \%$ \\
\hline LC & $0.859 \%$ & $0.859 \%$ & $0.859 \%$ & $0.859 \%$ & $0.858 \%$ & $0.857 \%$ & $2.118 \%$ & $2.116 \%$ & $2.116 \%$ & $2.116 \%$ & $2.113 \%$ & $3.597 \%$ & $2.112 \%$ \\
\hline LH & $1.157 \%$ & $1.157 \%$ & $1.157 \%$ & $1.156 \%$ & $1.156 \%$ & $1.156 \%$ & $3.149 \%$ & $3.150 \%$ & $3.149 \%$ & $3.145 \%$ & $3.147 \%$ & $8.063 \%$ & $3.148 \%$ \\
\hline C & $1.428 \%$ & $1.428 \%$ & $1.428 \%$ & $1.430 \%$ & $1.427 \%$ & $1.425 \%$ & $3.212 \%$ & $3.212 \%$ & $3.214 \%$ & $3.218 \%$ & $3.210 \%$ & $4.077 \%$ & $3.206 \%$ \\
\hline $\mathrm{s}$ & $1.184 \%$ & $1.186 \%$ & $1.185 \%$ & $1.187 \%$ & $1.184 \%$ & $1.183 \%$ & $3.164 \%$ & $3.169 \%$ & $3.165 \%$ & $3.171 \%$ & $3.162 \%$ & $4.149 \%$ & $3.159 \%$ \\
\hline w & $1.515 \%$ & $1.515 \%$ & $1.514 \%$ & $1.518 \%$ & $1.516 \%$ & $1.514 \%$ & $3.443 \%$ & $3.443 \%$ & $3.441 \%$ & $3.450 \%$ & $3.445 \%$ & $3.531 \%$ & $3.441 \%$ \\
\hline $\mathrm{CC}$ & $1.457 \%$ & $1.456 \%$ & $1.461 \%$ & $1.457 \%$ & $1.456 \%$ & $1.455 \%$ & $3.292 \%$ & $3.292 \%$ & $3.303 \%$ & $3.293 \%$ & $3.292 \%$ & $3.291 \%$ & $3.288 \%$ \\
\hline KC & $1.931 \%$ & $1.937 \%$ & $1.939 \%$ & $1.931 \%$ & $1.929 \%$ & $1.928 \%$ & $4.350 \%$ & $4.365 \%$ & $4.369 \%$ & $4.351 \%$ & $4.346 \%$ & $4.351 \%$ & $4.344 \%$ \\
\hline KW & $1.471 \%$ & $1.471 \%$ & $1.472 \%$ & $1.475 \%$ & $1.470 \%$ & $1.469 \%$ & $3.329 \%$ & $3.328 \%$ & $3.331 \%$ & $3.338 \%$ & $3.326 \%$ & $3.470 \%$ & $3.325 \%$ \\
\hline $\mathrm{CT}$ & $1.181 \%$ & $1.182 \%$ & $1.191 \%$ & $1.181 \%$ & $1.177 \%$ & $1.178 \%$ & $2.715 \%$ & $2.717 \%$ & $2.736 \%$ & $2.715 \%$ & $2.704 \%$ & $3.004 \%$ & $2.708 \%$ \\
\hline SB & $1.404 \%$ & $1.405 \%$ & $1.407 \%$ & $1.404 \%$ & $1.404 \%$ & $1.401 \%$ & $2.909 \%$ & $2.910 \%$ & $2.915 \%$ & $2.910 \%$ & $2.909 \%$ & $11.470 \%$ & $2.903 \%$ \\
\hline $\mathbf{L A}^{-}$ & $1.086 \%$ & $1.086 \%$ & $1.087 \%$ & $1.087 \%$ & $1.080 \%$ & $1.082 \%$ & $3.615 \%$ & $\overline{3.613 \%}$ & $3.616 \%$ & $3.618 \%$ & $3.595 \%$ & $3.644 \%$ & $3.600 \%$ \\
\hline LL & $1.381 \%$ & $1.381 \%$ & $1.381 \%$ & $1.380 \%$ & $1.379 \%$ & $1.377 \%$ & $4.585 \%$ & $4.585 \%$ & $4.585 \%$ & $4.583 \%$ & $4.579 \%$ & $4.574 \%$ & $4.573 \%$ \\
\hline LP & $1.226 \%$ & $1.226 \%$ & $1.226 \%$ & $1.229 \%$ & $1.217 \%$ & $1.219 \%$ & $4.067 \%$ & $4.067 \%$ & $4.068 \%$ & $4.078 \%$ & $4.035 \%$ & $4.058 \%$ & $4.042 \%$ \\
\hline GC & $1.058 \%$ & $1.058 \%$ & $1.057 \%$ & $1.059 \%$ & $1.058 \%$ & $1.055 \%$ & $2.586 \%$ & $2.586 \%$ & $2.586 \%$ & $2.589 \%$ & $2.587 \%$ & $2.771 \%$ & $2.581 \%$ \\
\hline LN & $1.748 \%$ & $1.746 \%$ & $1.747 \%$ & $1.747 \%$ & $1.747 \%$ & $1.746 \%$ & $5.786 \%$ & $5.780 \%$ & $5.784 \%$ & $5.786 \%$ & $5.784 \%$ & $5.856 \%$ & $5.781 \%$ \\
\hline SI & $1.793 \%$ & $1.793 \%$ & $1.795 \%$ & $1.791 \%$ & $1.793 \%$ & $1.790 \%$ & $4.004 \%$ & $4.004 \%$ & $4.009 \%$ & $4.000 \%$ & $4.004 \%$ & $4.243 \%$ & $3.998 \%$ \\
\hline LX & $1.367 \%$ & $1.367 \%$ & $1.368 \%$ & $1.370 \%$ & $1.366 \%$ & $1.366 \%$ & $4.540 \%$ & $4.540 \%$ & $4.544 \%$ & $4.550 \%$ & $4.537 \%$ & $4.542 \%$ & $4.537 \%$ \\
\hline$\overline{C L}^{-}$ & $1.823 \%$ & $1.823 \%$ & $1.823 \%$ & $1.825 \%$ & $1 . \overline{806 \%}$ & $1.807 \%$ & $6.380 \%$ & $\overline{6} . \overline{383 \%}$ & $6.381 \%$ & $6.388 \%$ & $\overline{6.322 \%}$ & $6.362 \%$ & $6.326 \%$ \\
\hline $\mathrm{CO}$ & $1.720 \%$ & $1.721 \%$ & $1.722 \%$ & $1.727 \%$ & $1.708 \%$ & $1.708 \%$ & $6.018 \%$ & $6.020 \%$ & $6.026 \%$ & $6.044 \%$ & $5.975 \%$ & $6.024 \%$ & $5.977 \%$ \\
\hline HO & $1.563 \%$ & $1.563 \%$ & $1.562 \%$ & $1.566 \%$ & $1.553 \%$ & $1.552 \%$ & $5.451 \%$ & $5.449 \%$ & $5.447 \%$ & $5.461 \%$ & $5.417 \%$ & $5.546 \%$ & $5.412 \%$ \\
\hline PG & $1.862 \%$ & $1.863 \%$ & $1.865 \%$ & $1.870 \%$ & $1.852 \%$ & $1.855 \%$ & $6.505 \%$ & $6.510 \%$ & $6.516 \%$ & $6.532 \%$ & $6.471 \%$ & $13.812 \%$ & $6.483 \%$ \\
\hline NG & $1.850 \%$ & $1.850 \%$ & $1.849 \%$ & $1.850 \%$ & $1.841 \%$ & $1.841 \%$ & $6.647 \%$ & $6.651 \%$ & $6.644 \%$ & $6.648 \%$ & $6.611 \%$ & $11.514 \%$ & $6.611 \%$ \\
\hline XB & $1.826 \%$ & $1.823 \%$ & $1.822 \%$ & $1.829 \%$ & $1.814 \%$ & $1.813 \%$ & $6.131 \%$ & $6.119 \%$ & $6.115 \%$ & $6.137 \%$ & $6.089 \%$ & $11.566 \%$ & $6.087 \%$ \\
\hline
\end{tabular}

Note: red bold values indicate that they are smallest in different forecasting methods. 
Table 9: Forecasting performance evaluated using functional and multivariate error measures for commodity futures forward curves at a monthly resolution.

\begin{tabular}{|c|c|c|c|c|c|c|c|c|c|c|c|c|c|}
\hline \multicolumn{14}{|c|}{ Validation Period } \\
\hline \multirow{2}{*}{ Symbol } & \multicolumn{6}{|c|}{ Functional Error } & \multicolumn{7}{|c|}{ Multivariate Error } \\
\hline & $\operatorname{FAR}(1)$ & $\operatorname{FAR}(2)$ & $\operatorname{FAR}(4)$ & FSAR & PF & Naïve & $\operatorname{FAR}(1)$ & $\operatorname{FAR}(2)$ & FAR(4) & FSAR & PF & DL & Naïve \\
\hline FC & 0.811 & 0.811 & 0.811 & 0.813 & 0.806 & 0.810 & 2.362 & 2.361 & 2.360 & 2.365 & 2.347 & 2.612 & 2.359 \\
\hline LC & 0.788 & 0.788 & 0.789 & 0.789 & 0.788 & 0.788 & 1.999 & 1.999 & 2.001 & 2.001 & 1.999 & 3.339 & 1.999 \\
\hline LH & 1.003 & 1.002 & 1.003 & 0.998 & 1.002 & 1.002 & 2.883 & 2.882 & 2.884 & 2.868 & 2.882 & 5.362 & 2.883 \\
\hline C & 9.279 & 9.273 & 9.278 & 9.300 & 9.266 & 9.269 & 22.156 & 22.145 & 22.158 & 22.212 & 22.124 & 25.480 & 22.129 \\
\hline s & 17.253 & 17.216 & 17.261 & 17.284 & 17.244 & 17.240 & 47.804 & 47.731 & 47.839 & 47.895 & 47.783 & 53.755 & 47.770 \\
\hline $\mathbf{w}$ & 15.291 & 15.266 & 15.277 & 15.261 & 15.259 & 15.257 & 36.401 & 36.359 & 36.392 & 36.344 & 36.318 & 42.133 & 36.320 \\
\hline $\mathrm{CC}$ & 45.103 & 45.116 & 45.136 & 45.191 & 45.108 & 45.090 & 107.016 & 107.056 & 107.113 & 107.236 & 107.028 & 106.966 & 106.987 \\
\hline $\mathrm{KC}$ & 2.785 & 2.792 & 2.791 & 2.790 & 2.789 & 2.789 & 6.543 & 6.560 & 6.560 & 6.557 & 6.554 & 6.605 & 6.553 \\
\hline KW & 14.752 & 14.748 & 14.750 & 14.729 & 14.674 & 14.692 & 35.068 & 35.067 & 35.072 & 35.000 & 34.894 & 40.150 & 34.938 \\
\hline $\mathrm{CT}$ & 1.671 & 1.673 & 1.664 & 1.671 & 1.670 & 1.669 & 4.021 & 4.024 & 4.001 & 4.021 & 4.017 & 4.616 & 4.016 \\
\hline SB & 0.401 & 0.402 & 0.403 & 0.402 & 0.400 & 0.400 & 0.900 & 0.902 & 0.905 & 0.902 & 0.897 & 4.680 & 0.898 \\
\hline $\mathbf{L A}^{-}$ & 38.359 & $38 . \overline{368}$ & 38.380 & 38.376 & 38.292 & $\overline{38.313}$ & 130.015 & 130.056 & $130 . \overline{10}$ & 130.074 & $\overline{129 . \overline{7} 9 \overline{6}}$ & $\overline{139.121}$ & 129.867 \\
\hline LL & 56.938 & 56.896 & 56.873 & 56.982 & 56.780 & 56.776 & 193.100 & 192.943 & 192.842 & 193.254 & 192.554 & 196.365 & 192.563 \\
\hline $\mathbf{L P}$ & 144.562 & 144.844 & 145.132 & 145.682 & 143.990 & 144.115 & 490.981 & 491.997 & 492.974 & 494.892 & 489.251 & 567.637 & 489.671 \\
\hline GC & 13.483 & 13.487 & 13.494 & 13.482 & 13.470 & 13.484 & 33.833 & 33.845 & 33.863 & 33.831 & 33.800 & 34.854 & 33.837 \\
\hline LN & 642.054 & 641.989 & 642.176 & 642.469 & 642.829 & 642.288 & 2167.377 & 2167.036 & 2167.389 & 2168.658 & 2169.989 & 2196.155 & 2168.522 \\
\hline SI & 0.525 & 0.525 & 0.525 & 0.525 & 0.524 & 0.524 & 1.202 & 1.202 & 1.203 & 1.202 & 1.201 & 1.253 & 1.201 \\
\hline LX & 61.565 & 61.568 & 61.677 & 61.652 & 61.634 & 61.587 & 206.857 & 206.856 & 207.214 & 207.162 & 207.099 & 211.740 & 206.982 \\
\hline $\mathrm{CL}^{-}$ & 1.698 & $\overline{1} . \overline{69}$ & 1.700 & 1.698 & 1.696 & $\overline{1.6} \overline{95}$ & $-\overline{5} . \overline{965}$ & 5.966 & $-\overline{5} . \overline{974}$ & 5.965 & $-\overline{5} . \overline{9} \overline{9}$ & $-\overline{6.183}$ & 5.956 \\
\hline $\mathrm{CO}$ & 1.647 & 1.647 & 1.648 & 1.650 & 1.644 & 1.644 & 5.828 & 5.828 & 5.833 & 5.839 & 5.817 & 6.083 & 5.816 \\
\hline HO & 4.518 & 4.520 & 4.519 & 4.517 & 4.511 & 4.508 & 15.716 & 15.723 & 15.718 & 15.711 & 15.691 & 16.627 & 15.682 \\
\hline PG & 3.841 & 3.843 & 3.854 & 3.854 & 3.840 & 3.843 & 13.824 & 13.826 & 13.865 & 13.868 & 13.817 & 21.254 & 13.828 \\
\hline NG & 0.182 & 0.182 & 0.182 & 0.182 & 0.181 & 0.181 & 0.640 & 0.640 & 0.640 & 0.641 & 0.640 & 1.281 & 0.638 \\
\hline $\mathrm{XB}$ & 3.999 & 4.000 & 4.005 & 3.999 & 4.003 & 4.002 & 13.535 & 13.538 & 13.550 & 13.532 & 13.548 & 18.342 & 13.542 \\
\hline
\end{tabular}

\begin{tabular}{|c|c|c|c|c|c|c|c|c|c|c|c|c|c|}
\hline \multirow[b]{2}{*}{ Symbol } & \multicolumn{6}{|c|}{ Functional Error } & \multicolumn{7}{|c|}{ Multivariate Error } \\
\hline & FAR(1) & FAR(2) & FAR(4) & FSAR & PF & Naïve & $\operatorname{FAR}(1)$ & FAR(2) & FAR(4) & FSAR & PF & DL & Naïve \\
\hline FC & 1.489 & 1.490 & 1.489 & 1.491 & 1.468 & 1.474 & 4.317 & 4.320 & 4.318 & 4.325 & 4.262 & 4.753 & 4.275 \\
\hline LC & 1.108 & 1.108 & 1.109 & 1.109 & 1.107 & 1.106 & 2.831 & 2.833 & 2.833 & 2.833 & 2.829 & 4.609 & 2.828 \\
\hline LH & 1.113 & 1.113 & 1.112 & 1.105 & 1.113 & 1.113 & 3.183 & 3.184 & 3.181 & 3.160 & 3.183 & 6.536 & 3.183 \\
\hline C & 7.172 & 7.172 & 7.176 & 7.188 & 7.159 & 7.154 & 17.251 & 17.252 & 17.264 & 17.283 & 17.212 & 22.825 & 17.200 \\
\hline S & 14.101 & 14.149 & 14.109 & 14.144 & 14.104 & 14.091 & 40.285 & 40.462 & 40.303 & 40.349 & 40.285 & 51.402 & 40.245 \\
\hline $\mathrm{W}$ & 8.970 & 8.969 & 8.965 & 8.995 & 8.977 & 8.967 & 21.281 & 21.280 & 21.271 & 21.341 & 21.297 & 22.098 & 21.275 \\
\hline $\mathrm{CC}$ & 34.477 & 34.478 & 34.561 & 34.478 & 34.477 & 34.452 & 82.256 & 82.259 & 82.466 & 82.269 & 82.258 & 82.303 & 82.197 \\
\hline $\mathrm{KC}$ & 3.072 & 3.082 & 3.084 & 3.071 & 3.067 & 3.066 & 7.197 & 7.220 & 7.226 & 7.195 & 7.187 & 7.165 & 7.184 \\
\hline KW & 9.083 & 9.076 & 9.086 & 9.101 & 9.072 & 9.070 & 21.492 & 21.475 & 21.498 & 21.534 & 21.464 & 22.620 & 21.458 \\
\hline CT & 0.848 & 0.849 & 0.855 & 0.849 & 0.847 & 0.847 & 2.078 & 2.079 & 2.095 & 2.079 & 2.075 & 2.326 & 2.074 \\
\hline SB & 0.235 & 0.236 & 0.236 & 0.235 & 0.235 & 0.235 & 0.515 & 0.515 & 0.516 & 0.515 & 0.515 & 1.943 & 0.513 \\
\hline LA & 20.335 & 20.328 & 20.340 & 20.350 & 20.223 & 20.247 & 68.829 & 68.805 & 68.846 & 68.881 & 68.440 & 69.021 & 68.521 \\
\hline LL & 27.799 & 27.801 & 27.802 & 27.791 & 27.787 & 27.732 & 94.218 & 94.228 & 94.232 & 94.196 & 94.180 & 93.950 & 93.990 \\
\hline LP & 77.716 & 77.712 & 77.805 & 78.066 & 77.114 & 77.323 & 262.505 & 262.492 & 262.793 & 263.692 & 260.398 & 262.281 & 261.171 \\
\hline GC & 14.264 & 14.262 & 14.260 & 14.265 & 14.267 & 14.240 & 35.713 & 35.706 & 35.702 & 35.720 & 35.720 & 38.432 & 35.649 \\
\hline LN & 236.250 & 235.929 & 235.993 & 236.187 & 236.189 & 236.065 & 795.819 & 794.784 & 795.006 & 795.583 & 795.618 & 799.975 & 795.193 \\
\hline SI & 0.406 & 0.406 & 0.407 & 0.406 & 0.406 & 0.406 & 0.940 & 0.940 & 0.941 & 0.939 & 0.940 & 0.986 & 0.938 \\
\hline LX & 28.941 & 28.933 & 28.967 & 29.012 & 28.923 & 28.926 & 98.055 & 98.027 & 98.151 & 98.300 & 97.997 & 98.190 & 98.009 \\
\hline CL & 1.130 & 1.130 & 1.131 & 1.132 & 1.123 & 1.123 & 3.988 & 3.989 & 3.990 & 3.994 & 3.964 & 3.990 & 3.963 \\
\hline $\mathrm{CO}$ & 1.122 & 1.122 & 1.123 & 1.127 & 1.116 & 1.115 & 3.965 & 3.967 & 3.969 & 3.985 & 3.946 & 3.989 & 3.943 \\
\hline HO & 3.055 & 3.056 & 3.055 & 3.059 & 3.041 & 3.037 & 10.673 & 10.675 & 10.671 & 10.687 & 10.627 & 10.832 & 10.611 \\
\hline PG & 3.282 & 3.283 & 3.285 & 3.296 & 3.260 & 3.273 & 11.513 & 11.516 & 11.525 & 11.561 & 11.439 & 22.135 & 11.480 \\
\hline NG & 0.066 & 0.066 & 0.066 & 0.066 & 0.066 & 0.066 & 0.233 & 0.233 & 0.234 & 0.234 & 0.233 & 0.373 & 0.233 \\
\hline XB & 3.333 & 3.333 & 3.333 & 3.341 & 3.322 & 3.320 & 11.221 & 11.221 & 11.221 & 11.248 & 11.185 & 19.216 & 11.180 \\
\hline
\end{tabular}

Note: red bold values indicate that they are smallest in different forecasting methods. 
Table 10: Relative forecasting performance evaluated using functional and multivariate error measures for commodity futures forward curves at a monthly resolution.

\begin{tabular}{|c|c|c|c|c|c|c|c|c|c|c|c|c|c|}
\hline \multicolumn{14}{|c|}{ Validation Period } \\
\hline \multirow[b]{2}{*}{ Symbol } & \multicolumn{6}{|c|}{ Functional Error } & \multicolumn{7}{|c|}{ Multivariate Error } \\
\hline & FAR(1) & FAR(2) & FAR(4) & FSAR & $\mathbf{P F}$ & Naïve & FAR(1) & FAR(2) & FAR (4) & FSAR & PF & DL & Naïve \\
\hline FC & $0.811 \%$ & $0.811 \%$ & $0.811 \%$ & $0.813 \%$ & $0.807 \%$ & $0.810 \%$ & $2.164 \%$ & $2.164 \%$ & $2.163 \%$ & $2.169 \%$ & $2.152 \%$ & $2.394 \%$ & $2.161 \%$ \\
\hline LC & $0.826 \%$ & $0.826 \%$ & $0.827 \%$ & $0.827 \%$ & $0.826 \%$ & $0.826 \%$ & $2.070 \%$ & $2.070 \%$ & $2.073 \%$ & $2.072 \%$ & $2.070 \%$ & $3.514 \%$ & $2.070 \%$ \\
\hline LH & $1.426 \%$ & $1.426 \%$ & $1.427 \%$ & $1.420 \%$ & $1.426 \%$ & $1.426 \%$ & $3.992 \%$ & $3.991 \%$ & $3.994 \%$ & $3.975 \%$ & $3.993 \%$ & $7.503 \%$ & $3.993 \%$ \\
\hline C & $2.051 \%$ & $2.049 \%$ & $2.051 \%$ & $2.055 \%$ & $2.047 \%$ & $2.047 \%$ & $4.629 \%$ & $4.626 \%$ & $4.630 \%$ & $4.640 \%$ & $4.620 \%$ & $5.093 \%$ & $4.619 \%$ \\
\hline $\mathbf{S}$ & $1.667 \%$ & $1.664 \%$ & $1.669 \%$ & $1.670 \%$ & $1.667 \%$ & $1.666 \%$ & $4.423 \%$ & $4.415 \%$ & $4.427 \%$ & $4.431 \%$ & $4.422 \%$ & $4.899 \%$ & $4.420 \%$ \\
\hline W & $2.233 \%$ & $2.232 \%$ & $2.234 \%$ & $2.234 \%$ & $2.230 \%$ & $2.229 \%$ & $5.065 \%$ & $5.064 \%$ & $5.067 \%$ & $5.070 \%$ & $5.059 \%$ & $5.787 \%$ & $5.056 \%$ \\
\hline $\mathrm{CC}$ & $1.848 \%$ & $1.849 \%$ & $1.849 \%$ & $1.849 \%$ & $1.848 \%$ & $1.846 \%$ & $4.157 \%$ & $4.159 \%$ & $4.160 \%$ & $4.161 \%$ & $4.157 \%$ & $4.145 \%$ & $4.154 \%$ \\
\hline KC & $1.768 \%$ & $1.773 \%$ & $1.773 \%$ & $1.768 \%$ & $1.768 \%$ & $1.768 \%$ & $3.982 \%$ & $3.994 \%$ & $3.993 \%$ & $3.982 \%$ & $3.982 \%$ & $3.986 \%$ & $3.981 \%$ \\
\hline KW & $2.069 \%$ & $2.068 \%$ & $2.069 \%$ & $2.069 \%$ & $2.066 \%$ & $2.063 \%$ & $4.664 \%$ & $4.661 \%$ & $4.664 \%$ & $4.664 \%$ & $4.655 \%$ & $5.375 \%$ & $4.649 \%$ \\
\hline $\mathrm{CT}$ & $1.860 \%$ & $1.864 \%$ & $1.862 \%$ & $1.861 \%$ & $1.859 \%$ & $1.859 \%$ & $4.197 \%$ & $4.204 \%$ & $4.197 \%$ & $4.198 \%$ & $4.194 \%$ & $4.639 \%$ & $4.193 \%$ \\
\hline SB & $2.249 \%$ & $2.256 \%$ & $2.261 \%$ & $2.255 \%$ & $2.246 \%$ & $2.246 \%$ & $4.631 \%$ & $4.645 \%$ & $4.656 \%$ & $4.643 \%$ & $4.624 \%$ & $20.847 \%$ & $4.624 \%$ \\
\hline$\overline{\mathbf{L A}}^{-}$ & $1.672 \%$ & $1.672 \%$ & $\overline{1.673 \%}$ & $1 . \overline{6} 71 \%$ & $1.669 \%$ & $1.6 \overline{6} 9 \overline{\%}$ & $5.565 \%$ & $\overline{5} . \overline{5} 6 \overline{7} \%$ & $5.568 \%$ & $5.561 \%$ & $\overline{5} . \overline{5} 56 \%$ & $5.871 \%$ & $5.555 \%$ \\
\hline LL & $2.786 \%$ & $2.784 \%$ & $2.784 \%$ & $2.787 \%$ & $2.778 \%$ & $2.778 \%$ & $9.246 \%$ & $9.241 \%$ & $9.238 \%$ & $9.252 \%$ & $9.222 \%$ & $9.360 \%$ & $9.219 \%$ \\
\hline $\mathbf{L P}$ & $2.296 \%$ & $2.300 \%$ & $2.306 \%$ & $2.311 \%$ & $2.286 \%$ & $2.288 \%$ & $7.621 \%$ & $7.633 \%$ & $7.652 \%$ & $7.670 \%$ & $7.586 \%$ & $8.458 \%$ & $7.594 \%$ \\
\hline GC & $1.400 \%$ & $1.400 \%$ & $1.401 \%$ & $1.399 \%$ & $1.399 \%$ & $1.399 \%$ & $3.426 \%$ & $3.425 \%$ & $3.427 \%$ & $3.422 \%$ & $3.423 \%$ & $3.552 \%$ & $3.424 \%$ \\
\hline LN & $2.860 \%$ & $2.859 \%$ & $2.857 \%$ & $2.862 \%$ & $2.861 \%$ & $2.858 \%$ & $9.436 \%$ & $9.432 \%$ & $9.426 \%$ & $9.445 \%$ & $9.439 \%$ & $9.490 \%$ & $9.431 \%$ \\
\hline SI & $2.590 \%$ & $2.589 \%$ & $2.590 \%$ & $2.592 \%$ & $2.587 \%$ & $2.586 \%$ & $5.790 \%$ & $5.788 \%$ & $5.790 \%$ & $5.795 \%$ & $5.784 \%$ & $6.198 \%$ & $5.781 \%$ \\
\hline LX & $2.589 \%$ & $2.588 \%$ & $2.594 \%$ & $2.591 \%$ & $2.591 \%$ & $2.588 \%$ & $8.555 \%$ & $8.552 \%$ & $8.571 \%$ & $8.560 \%$ & $8.559 \%$ & $8.660 \%$ & $8.552 \%$ \\
\hline $\bar{C} L^{-}$ & $2.142 \%$ & $2.144 \%$ & $2.150 \%$ & $2.141 \%$ & $2.139 \%$ & $2.137 \%$ & $7.518 \%$ & $7 . \overline{5} 24 \%$ & $7.547 \%$ & $7.514 \%$ & $7.508 \%$ & $7.741 \%$ & $7.501 \%$ \\
\hline $\mathrm{CO}$ & $2.035 \%$ & $2.036 \%$ & $2.041 \%$ & $2.037 \%$ & $2.029 \%$ & $2.028 \%$ & $7.118 \%$ & $7.121 \%$ & $7.142 \%$ & $7.124 \%$ & $7.098 \%$ & $7.377 \%$ & $7.093 \%$ \\
\hline HO & $1.958 \%$ & $1.960 \%$ & $1.961 \%$ & $1.957 \%$ & $1.951 \%$ & $1.949 \%$ & $6.865 \%$ & $6.870 \%$ & $6.875 \%$ & $6.861 \%$ & $6.839 \%$ & $7.267 \%$ & $6.832 \%$ \\
\hline PG & $1.470 \%$ & $1.471 \%$ & $1.475 \%$ & $1.475 \%$ & $1.468 \%$ & $1.469 \%$ & $5.112 \%$ & $5.112 \%$ & $5.127 \%$ & $5.128 \%$ & $5.103 \%$ & $7.807 \%$ & $5.108 \%$ \\
\hline NG & $2.405 \%$ & $2.403 \%$ & $2.404 \%$ & $2.406 \%$ & $2.401 \%$ & $2.396 \%$ & $8.814 \%$ & $8.809 \%$ & $8.813 \%$ & $8.818 \%$ & $8.800 \%$ & $16.751 \%$ & $8.783 \%$ \\
\hline $\mathrm{XB}$ & $1.573 \%$ & $1.573 \%$ & $1.574 \%$ & $1.571 \%$ & $1.573 \%$ & $1.572 \%$ & $5.296 \%$ & $5.297 \%$ & $5.301 \%$ & $5.291 \%$ & $5.297 \%$ & $7.111 \%$ & $5.294 \%$ \\
\hline \multicolumn{14}{|c|}{ Test Period } \\
\hline & \multicolumn{6}{|c|}{ Functional Error } & \multicolumn{7}{|c|}{ Multivariate Error } \\
\hline Symbol & $\operatorname{FAR}(1)$ & FAR(2) & FAR(4) & FSAR & $\mathbf{P F}$ & Naïve & $\operatorname{FAR}(1)$ & FAR(2) & FAR(4) & FSAR & PF & DL & Naïve \\
\hline FC & $1.016 \%$ & $1.017 \%$ & $1.016 \%$ & $1.018 \%$ & $1.003 \%$ & $1.005 \%$ & $2.701 \%$ & $2.703 \%$ & $2.700 \%$ & $2.706 \%$ & $2.668 \%$ & $2.951 \%$ & $2.672 \%$ \\
\hline LC & $0.894 \%$ & $0.894 \%$ & $0.894 \%$ & $0.894 \%$ & $0.893 \%$ & $0.892 \%$ & $2.229 \%$ & $2.231 \%$ & $2.231 \%$ & $2.231 \%$ & $2.227 \%$ & $3.597 \%$ & $2.226 \%$ \\
\hline LH & $1.443 \%$ & $1.443 \%$ & $1.443 \%$ & $1.432 \%$ & $1.443 \%$ & $1.443 \%$ & $3.971 \%$ & $3.971 \%$ & $3.969 \%$ & $3.936 \%$ & $3.971 \%$ & $8.063 \%$ & $3.970 \%$ \\
\hline C & $1.476 \%$ & $1.476 \%$ & $1.477 \%$ & $1.478 \%$ & $1.474 \%$ & $1.473 \%$ & $3.346 \%$ & $3.346 \%$ & $3.348 \%$ & $3.351 \%$ & $3.341 \%$ & $4.077 \%$ & $3.337 \%$ \\
\hline S & $1.235 \%$ & $1.239 \%$ & $1.237 \%$ & $1.239 \%$ & $1.235 \%$ & $1.234 \%$ & $3.359 \%$ & $3.371 \%$ & $3.362 \%$ & $3.366 \%$ & $3.358 \%$ & $4.149 \%$ & $3.354 \%$ \\
\hline w & $1.528 \%$ & $1.528 \%$ & $1.528 \%$ & $1.532 \%$ & $1.529 \%$ & $1.527 \%$ & $3.469 \%$ & $3.469 \%$ & $3.468 \%$ & $3.477 \%$ & $3.471 \%$ & $3.531 \%$ & $3.466 \%$ \\
\hline $\mathrm{CC}$ & $1.458 \%$ & $1.458 \%$ & $1.462 \%$ & $1.458 \%$ & $1.458 \%$ & $1.456 \%$ & $3.292 \%$ & $3.292 \%$ & $3.301 \%$ & $3.292 \%$ & $3.291 \%$ & $3.291 \%$ & $3.288 \%$ \\
\hline KC & $1.940 \%$ & $1.946 \%$ & $1.946 \%$ & $1.940 \%$ & $1.938 \%$ & $1.937 \%$ & $4.369 \%$ & $4.384 \%$ & $4.384 \%$ & $4.371 \%$ & $4.365 \%$ & $4.351 \%$ & $4.363 \%$ \\
\hline KW & $1.481 \%$ & $1.481 \%$ & $1.482 \%$ & $1.484 \%$ & $1.480 \%$ & $1.479 \%$ & $3.350 \%$ & $3.348 \%$ & $3.351 \%$ & $3.356 \%$ & $3.346 \%$ & $3.470 \%$ & $3.345 \%$ \\
\hline CT & $1.197 \%$ & $1.198 \%$ & $1.206 \%$ & $1.198 \%$ & $1.196 \%$ & $1.195 \%$ & $2.736 \%$ & $2.738 \%$ & $2.756 \%$ & $2.738 \%$ & $2.733 \%$ & $3.004 \%$ & $2.732 \%$ \\
\hline SB & $1.401 \%$ & $1.401 \%$ & $1.403 \%$ & $1.401 \%$ & $1.401 \%$ & $1.397 \%$ & $2.917 \%$ & $2.918 \%$ & $2.922 \%$ & $2.918 \%$ & $2.918 \%$ & $11.470 \%$ & $2.910 \%$ \\
\hline $\mathbf{L A}^{-}$ & $1.090 \%$ & $1.090 \%$ & $1.090 \%$ & $1.091 \%$ & $1.084 \%$ & $1.086 \%$ & $3.628 \%$ & $\overline{3.627 \%}$ & $3.629 \%$ & $3.631 \%$ & $\overline{3.608 \%}$ & $3.644 \%$ & $3.613 \%$ \\
\hline LL & $1.381 \%$ & $1.382 \%$ & $1.382 \%$ & $1.381 \%$ & $1.381 \%$ & $1.378 \%$ & $4.584 \%$ & $4.585 \%$ & $4.585 \%$ & $4.583 \%$ & $4.583 \%$ & $4.574 \%$ & $4.573 \%$ \\
\hline $\mathbf{L P}$ & $1.226 \%$ & $1.226 \%$ & $1.227 \%$ & $1.230 \%$ & $1.216 \%$ & $1.219 \%$ & $4.065 \%$ & $4.066 \%$ & $4.069 \%$ & $4.079 \%$ & $4.032 \%$ & $4.058 \%$ & $4.042 \%$ \\
\hline GC & $1.058 \%$ & $1.058 \%$ & $1.058 \%$ & $1.058 \%$ & $1.058 \%$ & $1.056 \%$ & $2.587 \%$ & $2.588 \%$ & $2.587 \%$ & $2.588 \%$ & $2.588 \%$ & $2.771 \%$ & $2.582 \%$ \\
\hline LN & $1.748 \%$ & $1.747 \%$ & $1.748 \%$ & $1.748 \%$ & $1.748 \%$ & $1.747 \%$ & $5.788 \%$ & $5.783 \%$ & $5.787 \%$ & $5.788 \%$ & $5.787 \%$ & $5.856 \%$ & $5.784 \%$ \\
\hline SI & $1.794 \%$ & $1.794 \%$ & $1.796 \%$ & $1.792 \%$ & $1.794 \%$ & $1.791 \%$ & $4.008 \%$ & $4.006 \%$ & $4.012 \%$ & $4.002 \%$ & $4.006 \%$ & $4.243 \%$ & $4.000 \%$ \\
\hline LX & $1.369 \%$ & $1.368 \%$ & $1.370 \%$ & $1.371 \%$ & $1.368 \%$ & $1.367 \%$ & $4.546 \%$ & $4.546 \%$ & $4.550 \%$ & $4.556 \%$ & $4.543 \%$ & $4.542 \%$ & $4.542 \%$ \\
\hline $\mathrm{CL}$ & $1.819 \%$ & $1.819 \%$ & $1.819 \%$ & $1.821 \%$ & $1.805 \%$ & $1.805 \%$ & $6.374 \%$ & $\overline{6} . \overline{377 \%} \overline{-}$ & $6.376 \%$ & $6.383 \%$ & $6.326 \%$ & $6.362 \%$ & $6.326 \%$ \\
\hline $\mathrm{CO}$ & $1.707 \%$ & $1.707 \%$ & $1.709 \%$ & $1.714 \%$ & $1.698 \%$ & $1.697 \%$ & $5.996 \%$ & $5.996 \%$ & $6.003 \%$ & $6.022 \%$ & $5.965 \%$ & $6.024 \%$ & $5.964 \%$ \\
\hline HO & $1.561 \%$ & $1.561 \%$ & $1.561 \%$ & $1.563 \%$ & $1.553 \%$ & $1.551 \%$ & $5.479 \%$ & $5.480 \%$ & $5.477 \%$ & $5.486 \%$ & $5.450 \%$ & $5.546 \%$ & $5.444 \%$ \\
\hline PG & $2.044 \%$ & $2.044 \%$ & $2.046 \%$ & $2.050 \%$ & $2.032 \%$ & $2.039 \%$ & $7.165 \%$ & $7.167 \%$ & $7.173 \%$ & $7.188 \%$ & $7.126 \%$ & $13.812 \%$ & $7.148 \%$ \\
\hline NG & $1.930 \%$ & $1.930 \%$ & $1.930 \%$ & $1.930 \%$ & $1.925 \%$ & $1.924 \%$ & $6.965 \%$ & $6.966 \%$ & $6.968 \%$ & $6.968 \%$ & $6.946 \%$ & $11.514 \%$ & $6.945 \%$ \\
\hline $\mathrm{XB}$ & $2.001 \%$ & $2.001 \%$ & $1.999 \%$ & $2.004 \%$ & $1.993 \%$ & $1.993 \%$ & $6.762 \%$ & $6.762 \%$ & $6.756 \%$ & $6.771 \%$ & $6.737 \%$ & $11.566 \%$ & $6.735 \%$ \\
\hline
\end{tabular}

Note: red bold values indicate that they are smallest in different forecasting methods. 


\section{Appendix C Sample Information}

Table 11: Data Information

\begin{tabular}{|c|c|c|c|c|c|c|c|}
\hline \multirow[b]{2}{*}{ Symbol } & \multicolumn{2}{|c|}{ Training Period } & \multicolumn{2}{|c|}{ Validation Period } & \multicolumn{2}{|c|}{ Test Period } & \multirow{2}{*}{$\begin{array}{c}\text { Total No. } \\
\text { of Obs. }\end{array}$} \\
\hline & Start & End & Start & End & Start & End & \\
\hline FC & 2000-01-04 & $2005-12-14$ & $2005-12-15$ & 2011-10-31 & 2011-11-01 & 2017-08-31 & 4406 \\
\hline LC & 2000-01-04 & 2005-11-28 & 2005-11-29 & 2011-10-13 & 2011-10-14 & 2017-08-31 & 4444 \\
\hline LH & 2000-01-04 & 2005-11-30 & 2005-12-01 & 2011-10-14 & $2011-10-17$ & 2017-08-31 & 4441 \\
\hline $\mathrm{C}$ & 2000-01-04 & $2005-11-23$ & $2005-11-25$ & 2011-10-12 & 2011-10-13 & $2017-08-31$ & 4447 \\
\hline $\mathrm{s}$ & 2000-01-04 & $2005-11-25$ & $2005-11-28$ & 2011-10-13 & 2011-10-14 & $2017-08-31$ & 4446 \\
\hline $\mathbf{w}$ & 2000-01-04 & $2005-11-23$ & $2005-11-25$ & 2011-10-12 & 2011-10-13 & $2017-08-31$ & 4447 \\
\hline $\mathrm{CC}$ & 2000-01-04 & 2005-12-05 & $2005-12-06$ & $2011-10-26$ & 2011-10-27 & $2017-08-31$ & 4416 \\
\hline KC & 2000-01-04 & 2005-12-06 & 2005-12-07 & 2011-10-25 & $2011-10-26$ & 2017-08-31 & 4418 \\
\hline KW & 2000-01-04 & $2005-12-21$ & $2005-12-22$ & $2011-10-26$ & 2011-10-27 & $2017-08-31$ & 4418 \\
\hline $\mathrm{CT}$ & 2000-01-04 & 2005-11-21 & $2005-11-22$ & 2011-10-18 & 2011-10-19 & $2017-08-31$ & 4433 \\
\hline SB & 2000-01-04 & 2005-12-05 & $2005-12-06$ & 2011-10-24 & $2011-10-25$ & $2017-08-31$ & 4422 \\
\hline$\overline{\mathbf{L}} \overline{\mathbf{A}}$ & $2000-01-\overline{0}$ & $2006-01-\overline{17}$ & $2006-01-18$ & $2011-11-08$ & $2011-11-09$ & $2017-08-\overline{31}$ & $-\overline{4}-\overline{-}$ \\
\hline LL & 2000-01-05 & 2006-11-30 & $2006-12-01$ & $2012-04-18$ & 2012-04-19 & $2017-08-31$ & 4071 \\
\hline $\mathbf{L P}$ & 2000-01-05 & 2006-03-07 & 2006-03-08 & $2011-12-01$ & $2011-12-02$ & $2017-08-31$ & 4351 \\
\hline GC & 2000-01-05 & $2005-12-02$ & $2005-12-05$ & 2011-10-19 & $2011-10-20$ & $2017-08-31$ & 4427 \\
\hline LN & 2000-01-05 & 2006-03-13 & 2006-03-14 & $2011-12-08$ & 2011-12-09 & $2017-08-31$ & 4337 \\
\hline SI & 2000-01-05 & $2005-12-06$ & $2005-12-07$ & $2011-10-20$ & $2011-10-21$ & $2017-08-31$ & 4429 \\
\hline LX & 2000-01-05 & $2006-02-27$ & $2006-02-28$ & 2011-12-02 & 2011-12-05 & $2017-08-31$ & 4348 \\
\hline$\overline{C L}$ & $2000-01-05$ & $2005-12-02$ & $2005-12-05$ & $2011-10-19$ & $2011-10-20$ & $2017-08-31$ & $-\overline{4} 22$ \\
\hline $\mathrm{CO}$ & 2000-01-05 & $2005-12-22$ & $2005-12-23$ & 2011-11-02 & 2011-11-03 & 2017-08-31 & 4508 \\
\hline HO & 2000-01-05 & 2005-12-06 & $2005-12-07$ & 2011-10-19 & 2011-10-20 & $2017-08-31$ & 4432 \\
\hline$P G$ & 2006-04-24 & $2010-10-06$ & $2010-10-07$ & 2014-03-19 & 2014-03-20 & $2017-08-31$ & 2668 \\
\hline NG & 2000-01-05 & 2005-12-05 & $2005-12-06$ & $2011-10-20$ & 2011-10-21 & $2017-08-31$ & 4421 \\
\hline XB & 2005-11-01 & 2009-10-13 & 2009-10-14 & 2013-09-20 & 2013-09-23 & $2017-08-31$ & 2980 \\
\hline
\end{tabular}

Note: The sample period is generally from January 2000 to August 2017. The whole sample is divided into three segments of equal length, namely training period, validation period, and test period. The difference in total number of observations is due to the two issues: 1) the trading of commodity futures operate in different holiday calendars and schedules; 2) we have removed the daily records with missing values. The data availability of PG and XB in Bloomberg starts from April 2006 and November 2005, respectively. 


\section{References}

Armstrong, W., Eddelbuettel, D., \& Laing, J. (2017). Rblpapi: R Interface to "Bloomberg". URL: https://CRAN.R-project.org/package=Rblpapi r package version 0.3.6.

Aue, A., Horváth, L., \& F. Pellatt, D. (2017). Functional generalized autoregressive conditional heteroskedasticity. Journal of Time Series Analysis, 38, 3-21.

Bai, J., \& Ng, S. (2019). Rank regularized estimation of approximate factor models. Journal of Econometrics, .

Baruník, J., \& Malinska, B. (2016). Forecasting the term structure of crude oil futures prices with neural networks. Applied Energy, 164, 366-379.

Bernardini, E., \& Cubadda, G. (2015). Macroeconomic forecasting and structural analysis through regularized reduced-rank regression. International Journal of Forecasting, 31, 682691.

Bessembinder, H., Coughenour, J. F., Seguin, P. J., \& Smoller, M. M. (1995). Mean reversion in equilibrium asset prices: evidence from the futures term structure. The Journal of Finance, $50,361-375$.

Bhardwaj, G., Gorton, G., \& Rouwenhorst, G. (2015). Facts and fantasies about commodity futures ten years later. Technical Report National Bureau of Economic Research.

Borovkova, S., \& Geman, H. (2006). Seasonal and stochastic effects in commodity forward curves. Review of Derivatives Research, 9, 167-186.

Bosq, D. (2000). Linear Processes in Function Spaces: Theory and Applications volume 149. Springer Science \& Business Media.

Box, G. E., \& Pierce, D. A. (1970). Distribution of residual autocorrelations in autoregressiveintegrated moving average time series models. Journal of the American statistical Association, $65,1509-1526$.

Byrne, J. P., Cao, S., \& Korobilis, D. (2017). Forecasting the term structure of government bond yields in unstable environments. Journal of Empirical Finance, 44, 209-225.

Chantziara, T., \& Skiadopoulos, G. (2008). Can the dynamics of the term structure of petroleum futures be forecasted? evidence from major markets. Energy Economics, 30, 962-985. 
Chong, T. T.-L., Tsui, S. C., \& Chan, W. H. (2017). Factor pricing in commodity futures and the role of liquidity. Quantitative Finance, 17, 1745-1757.

Diebold, F. X., \& Li, C. (2006). Forecasting the term structure of government bond yields. Journal of Econometrics, 130, 337-364.

Diebold, F. X., \& Rudebusch, G. D. (2013). Yield Curve Modeling and Forecasting: The Dynamic Nelson-Siegel Approach. Princeton University Press.

Duffee, G. et al. (2012). Forecasting interest rates. Handbook of Economic Forecasting, 2, $385-426$.

Duffie, D., Gray, S., \& Hoang, P. (1999). Volatility in energy prices. In Managing Energy Price Risk. 2. ed.

Dürr, R., \& Voegeli, M. (2009). Structural properties of commodity futures term structures and their implications for basic trading strategies. Available at SSRN: https://ssrn.com/abstract=1605211, .

Fritsch, F. N., \& Carlson, R. E. (1980). Monotone piecewise cubic interpolation. SIAM Journal on Numerical Analysis, 17, 238-246.

Fuertes, A.-M., Miffre, J., \& Fernandez-Perez, A. (2015). Commodity strategies based on momentum, term structure, and idiosyncratic volatility. Journal of Futures Markets, 35, 274-297.

Gabrys, R., \& Kokoszka, P. (2007). Portmanteau test of independence for functional observations. Journal of the American Statistical Association, 102, 1338-1348.

Gibson, R., \& Schwartz, E. S. (1990). Stochastic convenience yield and the pricing of oil contingent claims. The Journal of Finance, 45, 959-976.

Gomes, M. (2015). Harvesting commodity curve premiums through roll-yield differentials. The Journal of Alternative Investments, 18, 51-60.

Gorton, G., \& Rouwenhorst, K. G. (2006). Facts and fantasies about commodity futures. Financial Analysts Journal, 62, 47-68.

Gorton, G. B., Hayashi, F., \& Rouwenhorst, K. G. (2013). The fundamentals of commodity futures returns. Review of Finance, (pp. 35-105). 
Grith, M. M., Wagner, H. H., Härdle, W. K., \& Kneip, A. A. (2018). Functional principal component analysis for derivatives of multivariate curves. Statistica Sinica, 28, 2469-2496.

Grønborg, N. S., \& Lunde, A. (2016). Analyzing oil futures with a dynamic nelson-siegel model. Journal of Futures Markets, 36, 153-173.

Hall, P., \& Horowitz, J. L. (2007). Methodology and convergence rates for functional linear regression. Annals of Statistics, 35, 70-91.

Hansen, P. R., Lunde, A., \& Nason, J. M. (2011). The model confidence set. Econometrica, 79, $453-497$.

Hart, J. D. (1994). Automated kernel smoothing of dependent data by using time series crossvalidation. Journal of the Royal Statistical Society: Series B (Methodological), 56, 529-542.

Haugom, E., \& Ullrich, C. J. (2012). Forecasting spot price volatility using the short-term forward curve. Energy Economics, 34, 1826-1833.

Hörmann, S., Horváth, L., \& Reeder, R. (2013). A functional version of the arch model. Econometric Theory, 29, 267-288.

Hörmann, S., \& Kokoszka, P. (2012). Functional time series. In Handbook of statistics (pp. 157-186). Elsevier volume 30.

Horváth, L., Hušková, M., \& Rice, G. (2013). Test of independence for functional data. Journal of Multivariate Analysis, 117, 100-119.

Horváth, L., \& Kokoszka, P. (2012). Inference for functional data with applications volume 200. Springer Science \& Business Media.

Horváth, L., Kokoszka, P., \& Rice, G. (2014). Testing stationarity of functional time series. Journal of Econometrics, 179, 66-82.

Irwin, S. H., Garcia, P., Good, D. L., \& Kunda, E. (2009). Poor convergence performance of CBOT corn, soybean and wheat futures contracts: Causes and solutions. Available at SSRN: https://ssrn.com/abstract=1392380, .

Jin, X. (2017). Do futures prices help forecast the spot price? Journal of Futures Markets, 37, $1205-1225$. 
Kargin, V., \& Onatski, A. (2008). Curve forecasting by functional autoregression. Journal of Multivariate Analysis, 99, 2508-2526.

Kocagil, A. E., Swanson, N. R., \& Zeng, T. (2001). A new definition for time-dependent price mean reversion in commodity markets. Economics Letters, 71, 9-16.

Kogan, L., Livdan, D., \& Yaron, A. (2009). Oil futures prices in a production economy with investment constraints. The Journal of Finance, 64, 1345-1375.

Kokoszka, P., Rice, G., \& Shang, H. L. (2017). Inference for the autocovariance of a functional time series under conditional heteroscedasticity. Journal of Multivariate Analysis, 162, 32-50.

Litterman, R. B., \& Scheinkman, J. (1991). Common factors affecting bond returns. The Journal of Fixed Income, 1, 54-61.

Litzenberger, R. H., \& Rabinowitz, N. (1995). Backwardation in oil futures markets: Theory and empirical evidence. The Journal of Finance, 50, 1517-1545.

Moskowitz, T. J., Ooi, Y. H., \& Pedersen, L. H. (2012). Time series momentum. Journal of Financial Economics, 104, 228-250.

Mou, Y. (2010). Limits to arbitrage and commodity index investment: front-running the goldman roll, .

Ng, V. K., \& Pirrong, S. C. (1994). Fundamentals and volatility: Storage, spreads, and the dynamics of metals prices. Journal of Business, (pp. 203-230).

Pilipovic, D. (2007). Energy risk: Valuing and managing energy derivatives. McGraw Hill Professional.

Power, G. J., Eaves, J., Turvey, C., \& Vedenov, D. (2017). Catching the curl: Wavelet thresholding improves forward curve modelling. Economic Modelling, 64, 312-321.

Ramsay, J. O., \& Silverman, B. W. (2002). Applied functional data analysis. New York: Springer.

Routledge, B. R., Seppi, D. J., \& Spatt, C. S. (2000). Equilibrium forward curves for commodities. The Journal of Finance, 55, 1297-1338.

Samuelson, P. A. (1965). Proof that properly anticipated prices fluctuate randomly. IMR; Industrial Management Review (pre-1986), 6, 41. 
Schwartz, E., \& Smith, J. E. (2000). Short-term variations and long-term dynamics in commodity prices. Management Science, 46, 893-911.

Schwartz, E. S. (1997). The stochastic behavior of commodity prices: Implications for valuation and hedging. The Journal of Finance, 52, 923-973.

Sørensen, C. (2002). Modeling seasonality in agricultural commodity futures. Journal of Futures Markets, 22, 393-426.

The MathWorks, Inc. (2019). Financial Instruments Toolbox User's Guide. URL: https://uk. mathworks.com/help/pdf_doc/fininst/fininst.pdf (accessed May 1, 2019).

Tolmasky, C., \& Hindanov, D. (2002). Principal components analysis for correlated curves and seasonal commodities: The case of the petroleum market. Journal of Futures Markets, 22, 1019-1035.

Xiang, J., \& Zhu, X. (2013). A regime-switching nelson-siegel term structure model and interest rate forecasts. Journal of Financial Econometrics, 11, 522-555.

Zhang, X. (2016). White noise testing and model diagnostic checking for functional time series. Journal of Econometrics, 194, 76-95. 